\title{
2-Arachidonoylglycerol Reduces Proteoglycans and Enhances Remyelination in a Progressive Model of Demyelination
}

\author{
Ana Feliú, ${ }^{1}$ Itziar Bonilla del Río, ${ }^{3,4}$ Francisco Javier Carrillo-Salinas, ${ }^{1}$ CGloria Hernández-Torres, ${ }^{2}$ Leyre Mestre, ${ }^{1}$ \\ Nagore Puente, ${ }^{3,4} @$ Silvia Ortega-Gutiérrez, ${ }^{2}$ @Maria L. López-Rodríguez, ${ }^{2}$ Pedro Grandes, ${ }^{3,4,5}$ Miriam Mecha, ${ }^{1}$ \\ and Carmen Guaza ${ }^{1}$ \\ ${ }^{1}$ Functional and Systems Neurobiology Department, Neuroimmunology Group, Instituto Cajal, 28002 Madrid, Spain, ${ }^{2}$ Department of Organic Chemistry I, \\ Universidad Complutense de Madrid 28040 Madrid, Spain, ${ }^{3}$ Department of Neurosciences, University of the Basque Country UPV/EHU, E-48940 Leioa, \\ Spain, ${ }^{4}$ Achucarro Basque Center for Neuroscience Bizkaia, Science and Technology Park, E-48170 Zamudio, Spain, and ${ }^{5}$ Division of Medical Sciences, \\ University of Victoria, Victoria, British Columbia V8P 5C2, Canada
}

The failure to undergo remyelination is a critical impediment to recovery in multiple sclerosis. Chondroitin sulfate proteoglycans (CSPGs) accumulate at demyelinating lesions creating a nonpermissive environment that impairs axon regeneration and remyelination. Here, we reveal a new role for 2-arachidonoylglycerol (2-AG), the major CNS endocannabinoid, in the modulation of CSPGs deposition in a progressive model of multiple sclerosis, the Theiler's murine encephalomyelitis virus-induced demyelinating disease. Treatment with a potent reversible inhibitor of the enzyme monoacylglycerol lipase, which accounts for $85 \%$ of the 2-AG degradation in the mouse CNS, modulates neuroinflammation and reduces CSPGs accumulation and astrogliosis around demyelinated lesions in the spinal cord of Theiler's murine encephalomyelitis virus-infected mice. Inhibition of 2-AG hydrolysis augments the number of mature oligodendrocytes and increases MBP, leading to remyelination and functional recovery of mice. Our findings establish a mechanism for 2-AG promotion of remyelination with implications in axonal repair in CNS demyelinating pathologies.

Key words: 2-AG; chondroitin sulfate proteoglycans; neuroinflammation; oligodendrocytes; remyelination; TMEV-IDD

Significance Statement

The deposition of chondroitin sulfate proteoglycans contributes to the failure in remyelination associated with multiple sclerosis. Here we unveil a new role for 2-arachidonoylglycerol, the major CNS endocannabinoid, in the modulation of chondroitin sulfate proteoglycan accumulation in Theiler's murine encephalomyelitis virus-induced demyelinating disease. The treatment during the chronic phase with a potent reversible inhibitor of the enzyme monoacylglycerol lipase, which accounts for $85 \%$ of the 2-arachidonoylglycerol degradation in the mouse CNS, modulates neuroinflammation and reduces chondroitin sulfate proteoglycan deposition around demyelinated lesions in the spinal cord of Theiler's murine encephalomyelitis virus-infected mice. The increased 2-arachidonoylglycerol tone promotes remyelination in a model of progressive multiple sclerosis ameliorating motor dysfunction.

\section{Introduction}

Multiple sclerosis (MS) is a clinically heterogeneous CNS disease (Lassmann et al., 2001) characterized by inflammation, demyeli-

Received Sept. 15, 2016; revised June 26, 2017; accepted July 12, 2017.

Author contributions: M.M. and C.G. designed research; A.F., I.B., and F.J.C.-S. performed research; G.H.-T., N.P., S.O.-G., M.L.-R., and P.G. contributed unpublished reagents/analytic tools; A.F., I.B., L.M., and M.M. analyzed data; C.G. wrote the paper.

This work was supported by Ministry of the Economy and Competition (MINECO) Grants SAF2013-42784-R and SAF2016-76449-R, Comunidad de Madrid Grant S2011/BMD-2308, and Red Española de Esclerosis Múltiple Grants RD12/0032/0008 and RD16/0015/0021 (sponsored by the Fondo de Investigación Sanitaria) to C.G., Basque Government Grant IT764-13, MINEC0/FEDER Grant SAF2015-65034-R, and University of the Basque Country Grant nation, axonal damage, and gliosis (Compston and Coles, 2008). Most patients with MS initially develop a relapsing-remitting dis-

UPV/EHU UFI11/41 to P.G., and MINECO Grant SAF2013-48271-C2-1-R to M.L.-R. None of the funding bodies played any role in the study design, data collection and analysis, the decision to publish, or the preparation of the manuscript. A.F. is a predoctoral fellow supported by MINECO Grant BES-2014-068459. We thank Laura Ramos for excellent technical support.

The authors declare no competing financial interests.

Correspondence should be addressed to either Dr. Miriam Mecha or Dr. Carmen Guaza, Instituto Cajal, Av. Doctor Arce 37, 28002 Madrid, Spain. E-mail: miriammecha@cajal.csic.es or cgjb@cajal.csic.es.

DOI:10.1523/JNEUROSCI.2900-16.2017

Copyright $\odot 2017$ the authors $\quad 0270-6474 / 17 / 378385-14 \$ 15.00 / 0$ 
ease followed by a secondary progressive clinical course; however, $10 \%-15 \%$ of MS patients develop a primary progressive course for which there are scarce treatments available yet despite intense research. In MS, repair and remyelination occurs spontaneously in shadow plaques (Chang et al., 2012); but as the disease progresses, remyelination becomes less efficient (Chang et al., 2002; Franklin, 2002; Goldschmidt et al., 2009) and the patients' disability augments. Demyelinated areas develop reactive astroglial scars (Frischer et al., 2015) that express and organize extracellular matrix proteins and chondroitin sulfate proteoglycans (CSPGs) that accumulates impeding neuronal growth and remyelination in MS (Sobel and Ahmed, 2001; Back et al., 2005; Chang et al., 2012). A basal level of CSPGs production is necessary to maintain the extracellular matrix in a state that ensures synaptic stabilization and plasticity (Carulli et al., 2006; Galtrey and Fawcett, 2007). Following injury, CSPGs are immediately upregulated to limit tissue damage (Silver and Miller, 2004); however, when CSPGs accumulation persists in chronic phases, the spontaneous reparative mechanisms are inhibited (Siebert and Osterhout, 2011; Lau et al., 2012). CSPGs clearance correlates with remyelination and axon regeneration in different experimental conditions of demyelination and spinal cord injury (Siebert et al., 2011; Lau et al., 2012; Bartus et al., 2014; Dyck et al., 2015; Lang et al., 2015; Keough et al., 2016).

Theiler's murine encephalomyelitis virus-induced demyelinating disease (TMEV-IDD) is a well-established progressive model of MS (Lipton and Dal Canto, 1976) with limited remyelination associated with insufficient oligodendrocytes differentiation (U1rich et al., 2008). Moreover, it also has been described that the chronic demyelination phase is accompanied by astrogliosis and alterations of extracellular matrix composition (Haist et al., 2012; Feliu et al., 2015), that may in turn contribute to the failure in remyelination.

Endogenous and exogenous cannabinoids protect oligodendrocytes from inflammatory damage (Molina-Holgado et al., 2002; Gómez et al., 2010; Mecha et al., 2012). The endogenous cannabinoid 2-arachidonoylglycerol (2-AG) promotes the differentiation of oligodendrocyte progenitor cells (OPCs) (Gómez et al., 2011), increases OPC proliferation (Gómez et al., 2015), and decreases oligodendrocyte excitotoxicity (Bernal-Chico et al., 2015). In the present study, we unveil a new role of $2-A G$ as modulator of CSPGs production by administering UCM03025, a potent reversible inhibitor of monoacylglycerol lipase (MAGL), the main enzyme responsible for 2-AG hydrolysis (Hernández-Torres et al., 2014). In the light of our findings, suppressed CSPGs deposition, reduced inflammation, decreased axonal loss, remyelination, and functional motor rescue in TMEV-IDD, we underlie the importance of the endocannabinoid system as a novel strategy to enhance endogenous reparative mechanisms in demyelinating conditions.

\section{Materials and Methods}

Animals and Theiler's virus infection. TMEV-IDD susceptible female SJL/J mice (Envigo) were maintained at our in-house colony (Instituto Cajal, Madrid) under standard conditions: a $12 \mathrm{~h}$ light/dark cycle, a temperature of $20^{\circ} \mathrm{C}\left( \pm 2^{\circ} \mathrm{C}\right), 40 \%-50 \%$ relative humidity, ad libitum access to food and water. Four-week-old mice were inoculated intracerebrally in the right hemisphere with $2 \times 10^{6}$ plaque-forming units ( $\mathrm{pfu}$ ) of the Daniel's strain of TMEV diluted in $30 \mu \mathrm{l}$ of DMEM and supplemented with 10\% FCS (Lledó et al., 1999). Sham-operated mice received $30 \mu \mathrm{l}$ of DMEM with 10\% FCS alone. All experiments were performed in accordance with EU (Directive 2010/63/EU) and National (Royal Decree53/2013 BOE No. 34 and Comunidad de Madrid: ES 280790000184) guidelines, and the Ethics Committee on Animal Experimentation at the
Instituto Cajal approved all the procedures described in this study (protocol number 2013/03 CEEA-IC).

Pharmacological treatments. TMEV-infected mice were administered with xyloside (4-methylumbelliferyl- $\beta$-D-xylopyranoside; Sigma-Aldrich) an inhibitor of CSPGs synthesis at a dose of $(2.4 \mathrm{mg} / \mathrm{animal} / \mathrm{d}$, i.p. $)$ once daily for 10 consecutive days as described by previous studies (Lau et al., 2012). Another group of animals were treated with UCM03025, an inhibitor of 2-AG degradation (Department of Organic Chemistry, Universidad Complutense de Madrid) at a dose of $5 \mathrm{mg} / \mathrm{kg}$ intraperitoneally on the basis of previous studies (Hernández-Torres et al., 2014) once daily for 10 consecutive days. All treatments were administered during the chronic phase of the disease when signs of disease were evident (from day 75 to day 85 after infection [dpi]). The duration of treatment with UCM03025 was chosen based on previous studies using the TMEV-IDD model (Docagne et al., 2007). Two independent experiments were performed simultaneously for UCM03025 treatment analysis, studying 5 or 6 animals per group at each time point, and the control animals received the vehicle alone (DMSO/saline). In the case of xyloside treatment, 5 or 6 animals per group at each time point were used and control animals received vehicle alone (DMSO in phosphate buffer). In an additional experiment, mice were administered the $\mathrm{CB} 1$ receptor antagonist AM251 ( $2 \mathrm{mg} / \mathrm{kg}$, i.p., Tocris Bioscience) or the CB2 receptor antagonist AM630 ( $2 \mathrm{mg} / \mathrm{kg}$, i.p., Tocris Bioscience) $30 \mathrm{~min}$ before UCM03025 treatment. To assess whether administration of the inhibitor of 2-AG hydrolysis may affect remyelination other group of mice was treated with UCM03025 for $10 \mathrm{~d}(75-85 \mathrm{dpi})$ and then killed at $105 \mathrm{dpi}$. We selected this time based on our previous work (Areválo-Martín et al., 2003). BrdU (50 mg/kg, i.p., Sigma-Aldrich) was administered on a daily basis for $10 \mathrm{~d}$, together with UCM03025 or the vehicle. The animal's spontaneous motor activity was assessed at 85 or $105 \mathrm{dpi}$, and they were then killed with an overdose of anesthetic for tissue collection.

Surgery, placement of ventricular catheters and miniosmotic pumps for 2-AG delivery. Alzet miniosmotic pumps (model 1002, mean pumping rate/flow $0.26 \mu \mathrm{l} / \mathrm{h}$, with a 14 day capacity and a total loaded volume of $101 \mu \mathrm{l}$ ) and brain infusion kits (polyvinylchloride tubing attached to an infusion cannula) were obtained from Alzet. Miniosmotic pumps were assembled for intracerebroventricular infusion according to the manufacturer's instructions, and they were attached to an infusion cannula ( $4 \mathrm{~cm}$ tubing) and a 28 gauge 5 -mm-long needle. Briefly, mice were deeply anesthetized and placed in a stereotaxic frame, and the catheter was inserted into the ventricle (anteroposterior: -0.6 ; mediolateral: 1 ; dorsoventral: 1.8) and secured with surgical cement. 2-AG (5 mg/kg, Tocris Bioscience) or vehicle-loaded pumps (DMSO/ethanol/PBS) were implanted subcutaneously into the back of sham and TMEV-infected mice, and they were connected directly to the catheter placed appropriately in the ventricle. The pumps delivered their load over $10 \mathrm{~d}$, from 75 to $85 \mathrm{dpi}$; and in the case of mice maintained to $105 \mathrm{dpi}$, the pumps were removed once the treatment had finished at $85 \mathrm{dpi}$.

Anterograde BDA tracing. Mice that were treated for $10 \mathrm{~d}$ with UCM03025 and maintained until $105 \mathrm{dpi}$ were deeply anesthetized $15 \mathrm{~d}$ before death, and placed in a stereotaxic frame to bilaterally inject the highresolution anterograde tracer BDA (10,000 MW lysine-fixable dextran biotin amine, Invitrogen), administering $1.2 \mu \mathrm{l}$ of $10 \% \mathrm{w} / \mathrm{v}$ BDA solution diluted in $0.01 \mathrm{~m}$ phosphate buffer (PB). BDA was injected into both motor cortices through a $5 \mu$ l gauge Hamilton needle lowered through the cortex $(1 \mathrm{~mm})$. Four injections were administered bilaterally $(0.3 \mu \mathrm{l}$ per site) within a perimeter defined coronally by bregma $1.7 \mathrm{~mm}$ to -0.7 $\mathrm{mm}$ and $0.5-1.5 \mathrm{~mm}$ from sagittal suture. Injections were performed over 3-5 min, and the needle was removed slowly. The mice were killed $15 \mathrm{~d}$ after BDA injection (Rolls et al., 2008).

Spontaneous motor activity. Mice were followed for the development and progression of demyelinating disease by evaluation of spontaneous motor function. The effects of xyloside and the inhibitor of MAGL were evaluated at the end of the treatment $(85 \mathrm{dpi})$ or $20 \mathrm{~d}$ after cessation of treatment (105 dpi). The screening for locomotor activity was performed using an activity cage (Activity Monitor System, Omnitech Electronics) coupled to a Digiscan Analyzer to evaluate spontaneous motor activity. Data for horizontal (HACTV) and vertical activity (VACTV) were obtained as the total number of beam interruptions in the horizontal and 
vertical sensor in a $10 \mathrm{~min}$ session. The percentage of disability was calculated by comparing motor performance before and after treatment per animal and was analyzed in relation with the grade of motor dysfunction of TMEV mice.

Tissue processing. Mice were anesthetized with pentobarbital (Dolethal, $50 \mathrm{mg} / \mathrm{kg}$ body weight, i.p.) and perfused transcardially with saline $0.9 \%$. The spinal cord was obtained by extrusion with saline. Cervical spinal cord was immediately frozen and kept at $-80^{\circ} \mathrm{C}$ for Western blotting and RT-PCR analysis, the remaining spinal cord was fixed overnight in $4 \%$ PFA prepared in $0.1 \mathrm{M} \mathrm{PB}$, and cryoprotected in a sucrose solution prepared in $0.1 \mathrm{M} \mathrm{PB} \mathrm{(15 \%} \mathrm{followed} \mathrm{by} \mathrm{a} 30 \%$ solution). Cervical coronal spinal cord cryostat sections ( $30 \mu \mathrm{m}$ thick, Leica Microsystems CM1900 cryostat) were then processed for immunohistochemistry. For BDA tracing, the cervical spinal cords were embedded in Agar (Conda) after fixation overnight in $4 \%$ PFA, and sections ( $50 \mu \mathrm{m}$ thick) were obtained on a Leica VT1000S vibratome (Leica Microsystems).

Immunohistochemistry. For immunofluorescence analysis, free-floating cervical spinal cord cryostat sections were washed with $0.1 \mathrm{M} \mathrm{PB}$, followed by $\mathrm{PB}+0.2 \%$ Triton $\mathrm{X}-100$ (PBT), and they were then blocked for $1 \mathrm{~h}$ at room temperature in blocking buffer (PBT and 5\% normal goat serum, Vector Laboratories). Astrocytes were stained with GFAP (1:1000; Sigma-Aldrich, \#G9269) and vimentin antibody (1:1000; Sigma-Aldrich, \#HPA001762). MBP (1:500; Millipore, \#MAB382) was used to detect myelin, Olig-2 to stain OPCs (1:250; \#sc19967 Santa Cruz Biotechnology), CC1 antibody to stain mature oligodendrocytes (1:250; \#OP80 Calbiochem), Iba-1 antibody was used to detect microglia (1:1000; \#019-19741 Wako), all incubated overnight at $4^{\circ} \mathrm{C}$. CSPGs were detected with an anti-chondroitin sulfate antibody (CS-56 1:200; \#C8035, SigmaAldrich) that recognizes the terminal portions of the chondroitin sulfate-4 or -6 side chains; thus, it detects a variety of CSPGs (Avnur and Geiger, 1984). In this case, the antibody was incubated for $1 \mathrm{~h}$ at room temperature and overnight at $4^{\circ} \mathrm{C}$. Axon integrity was assessed by staining with Neurofilament-H (Millipore, \#ABN76). To detect the thymidine analog, $\mathrm{BrdU}$ (1:250; \#ab6326 Abcam), the tissue was permeabilized with $\mathrm{HCl}$ $2 \mathrm{~N}$ for $45 \mathrm{~min}$ before antibody incubation. After incubation with the primary antibodies, the sections were rinsed in PBT, and they were then incubated with an AlexaFluor-488-conjugated goat anti-rabbit (for vimentin), goat anti-mouse (for MBP), or goat anti-rat antibody (for BrdU), with an AlexaFluor-594-conjugated goat anti-rabbit antibody (for GFAP and Olig-2, Invitrogen), goat anti-mouse antibody (for CC1) or with a Texas Red-conjugated donkey anti-mouse IgM (for CS-56, Jackson ImmunoResearch Laboratories). For histological assessment of the BDA tracing, an avidin HRP-conjugated antibody was used in conjunction with the 3,3' diaminobenzidine tetrahydrochloride chromogen (Sigma-Aldrich). In all cases, the specificity of staining was confirmed by omitting the primary antibody.

Inflammatory infiltrates analysis. The cervical spinal cord sections were stained with H\&E to analyze the infiltrates in the parenchyma. Inflammatory infiltrates were evaluated by scoring the infiltrate in the spinal cord on a scale of 0 to 4 : a score of 0 reflects the absence of infiltrates; 4 reflects the maximal infiltrate; while the intermediate scores of 1,2 , and 3 define the increasing infiltrate density in the tissue (Feliu et al., 2015).

$R T-P C R$. Total RNA was extracted from the cervical spinal cords using a chloroform and ethanol RNA extraction protocol and RNeasy mini columns (QIAGEN), avoiding genomic DNA contamination by DNase I degradation (DNase I; Sigma-Aldrich). The RNA yield was determined using a Nanodrop spectrophotometer (Thermo Scientific), and total RNA ( $1 \mu \mathrm{g}$ in $20 \mu \mathrm{l}$ ) was reverse transcribed into cDNA using poly-dT primers and a reverse transcription kit (Promega Biotech Ibérica). Realtime PCR was performed with SYBR and the oligonucleotide mouse primer sequences were as follows: brevican, forward 5'CCATCCA GAACCCACGAGA3', reverse 5'-ACCCACCACTCCGTAATTCC-3'; neurocan, forward 5' -CGGATGAAGTGGACTAAGGTT-3', reverse 5' 'CGCACCACGTTGTCTTTGG-3'; phosphacan, forward 5'-TCCTCG CGTGCGTTCAG-3', reverse 5'-ATAGGACCAGCCAATCTCTTCA-3'; Olig2, forward 5' -GACTCCCCCCTCCGTCTAAG-3', reverse 5' -CGC AGTAAAGCCCACGTTGT-3'; Nkx2.2, forward 5'-CGCCGACACAGG TCAAGAT-3', reverse 5'-CCATCCGTCGGTTTTGAAAT-3'; IL-1 $\beta$, forward 5' ${ }^{\prime}$ TGG TGT GTG ACG TTC CCA TT- ${ }^{\prime}$, reverse $5^{\prime}$-TCC ATT
GAG GTG GAG AGC TTT C-3'; TNF- $\alpha$, forward 5' ${ }^{\prime}$-AGA GGC ACT CCC CCA AAA GA-3', reverse 5' -CGA TCA CCC CGA AGT TCA GT-3'; NOS-II, forward 5'-CCCTTCAATGGTTGGTACATG-3', reverse 5'-ACA TTGATCTCCGTGACAGCC-3' (Integrated DNA Technologies); Arg-1 (Mm 00475988; TaqMan, Applied Biosystems). After an initial incubation at $50^{\circ} \mathrm{C}$ for $2 \mathrm{~min}$ and $95^{\circ} \mathrm{C}$ for $10 \mathrm{~min}$, PCR amplification was performed over $40 \mathrm{cycles}$ of $95^{\circ} \mathrm{C}$ for $15 \mathrm{~s}$ and $60^{\circ} \mathrm{C}$ for $1 \mathrm{~min}$. The samples were assayed in triplicate on an Applied Biosystems PRISM 7500 Sequence detection system. To rule out genomic DNA contamination, a control sample using RNA that had not been reversely transcribed was used as the template for each set of extractions. Gene expression was calculated using the $2^{-\Delta \Delta \mathrm{Ct}}$ method, and the relative expression was quantified by calculating the ratio between the values obtained for each gene of interest and those of the RPS29 gene (forward 5' -GCCGCGTCTGCTCCAA-3', reverse 5' ACATGTTCAGCCCGTATTTGC-3'). The results are expressed as a percentage with respect to sham animals for each time point.

Western blotting. Cervical spinal cord from sham and TMEV-infected animals were lysed with RIPA buffer (TBS, pH 7.6, containing 10\% glycerol, 1\% Nonidet P-40, 1 mm EDTA, 1 mM EGTA) and complete protease inhibitors mixture (Roche Diagnostics). The samples were sonicated and centrifuged for $15 \mathrm{~min}$ at 13,500 rpm. In the case of CSPGs detection, samples were resuspended in chondroitinase $\mathrm{ABC}$ buffer $(50 \mathrm{~mm}$ Tris $\mathrm{pH}$ 8.0, $60 \mathrm{~mm}$ sodium acetate, $0.02 \% \mathrm{BSA}$ ) and treated for $3 \mathrm{~h}$ at $37^{\circ} \mathrm{C}$ with $0.1 \mathrm{U} / \mathrm{ml}$ Chondroitinase ABC from Proteus vulgaris (Sigma-Aldrich). This reaction was stopped by adding $5 \times$ Laemmli buffer and boiled for $10 \mathrm{~min}$. The proteins ( $15 \mu \mathrm{g}$ of protein) were then resolved on a $6 \%$ SDS-polyacrylamide gel and transferred at $4^{\circ} \mathrm{C}$ to a nitrocellulose membrane (GE Healthcare). In the case of myelin MBP detection, samples were resuspended in $5 \times$ Laemmli buffer and boiling for $10 \mathrm{~min}, 15 \mu \mathrm{g}$ of protein was loaded on a $12 \%$ SDS-polyacrylamide gel and transferred at $4^{\circ} \mathrm{C}$ to a nitrocellulose membrane. The membranes were washed with TBS followed by further washes with TBS with $0.1 \%$ Tween 20 (TBST). The membranes were blocked for $1 \mathrm{~h}$ in 5\% (Nonfat dried milk, PanReac AppliChem) in TBST, and they were probed overnight for neurocan (1:1000; \#1F6 DSHB, University of Iowa, Ames, IA), brevican (1:1000; \#610894 BD Bioscience), phosphacan (IgM 1:1000; \#MAB5210 Millipore), and MBP (1:500 Millipore). The membranes were then washed in blocking solution and incubated with a secondary HRP-conjugated goat anti-mouse IgG or goat anti-mouse IgM antibody for $1 \mathrm{~h}$ (1:2000; BioRad). The membranes were washed with TBST and TBS. Protein bands were visualized by enhanced chemiluminescence detection and the amount of protein was estimated by densitometry (GS800 calibrated densitometer; Bio-Rad) and corrected for tubulin (anti- $\alpha$-tubulin (1: 10,000; \#T5168 Sigma-Aldrich) or anti-pan-actine (1:1000; \#D18C11 Cell Signaling Technology). The blots were stripped in $62.5 \mathrm{~mm}$ Tris- $\mathrm{HCl}, \mathrm{pH} 6.8$, containing 2\% SDS and 0.7\% 2-mercaptoethanol and by each antibody.

Tissue processing for transmission electron microscopy (TEM). Mice (105 dpi) were housed under standard conditions (food and water ad libitum; 12 h/12 h light/dark cycle). Sham, TMEV mice, and UCM03025-treated TMEV mice (two each) were deeply anesthetized by intraperitoneal injection of ketamine/xylazine $(80 / 10 \mathrm{mg} / \mathrm{kg}$ body weight) and transcardially perfused at room temperature $\left(20^{\circ} \mathrm{C}-25^{\circ} \mathrm{C}\right)$ with $\mathrm{PBS}(0.1 \mathrm{M}, \mathrm{pH} 7.4)$ for $20 \mathrm{~s}$, followed by the fixative solution made up of $4 \%$ formaldehyde (freshly depolymerized from PFA), $0.2 \%$ picric acid, and $0.1 \%$ glutaraldehyde in phosphate buffer $(0.1 \mathrm{M}, \mathrm{pH} 7.4)$ for $10-15 \mathrm{~min}$. Then, spinal cords were removed and postfixed in the fixative solution for $\sim 1$ week at $4^{\circ} \mathrm{C}$ and stored at $4^{\circ} \mathrm{C}$ in the $1: 10$ diluted fixative solution until use.

Cervical spinal cord sections were cut at $50 \mu \mathrm{m}$ in a vibratome and collected in a $0.1 \mathrm{~m}$ phosphate buffer at room temperature. They were osmicated ( $1 \%$ osmium tetroxide, in $0.1 \mathrm{~m}$ phosphate buffer, $\mathrm{pH} 7.4$, $20 \mathrm{~min}$ ), dehydrated in graded alcohols to propylene oxide, and plasticembedded in Epon resin 812. The $50 \mathrm{~nm}$ ultrathin sections were collected on mesh nickel grids, stained with $2.5 \%$ lead citrate for $20 \mathrm{~min}$, and examined in a Philips EM208S electron microscope.

Semiquantification of axons by TEM. White matter fields were photographed by using a digital Olympus SIS Morada camera coupled to Philips EM208S electron microscope. A total of 1000 axons and axons plus myelin from the ventral horn white matter of cervical spinal cords were analyzed for each group (sham, TMEV mice, and UCM03025- 
treated TMEV mice). The number of myelinated and demyelinated axons was counted, and the g-ratio was calculated for myelinated axons in each experimental group. g-ratio is defined as the ratio of the diameter of a given axon and the diameter of the axon plus myelin unit. Axon portions with well-preserved and compacted myelin were measured with the ImageJ software (1.43u version, National Institutes of Health) by drawing two perpendicular diameters from each axon and axon plus myelin.

Microscopy and image analysis. Immunofluorescence images were acquired on a Leica TCS SP5 confocal microscope, and immunohistochemical staining was assessed with a Zeiss Axiocam high-resolution digital color camera. Individual optical sections were examined by analyzing ventral horn white matter of 5 or 6 cervical spinal cord sections from at least 5 or 6 animals per group. Staining was quantified using ImageJ software, maintaining the threshold intensity constant to compare the experimental and control images obtained within the experiments. The data are presented as the percentage of the total area stained with respect to the sham animals. The quantification of labeled cells was evaluated per square millimeter in the ventral horn white matter spinal cord.

Data analysis. All the data are expressed as the mean \pm SEM and the SPSS 22 software (IBM) was used for the statistical analysis. One-way ANOVA followed by the Bonferroni and Tukey's post hoc tests and unpaired two-tailed student $t$ test were used to determine the statistical significance. Kruskal-Wallis test and Mann-Whitney $U$ test were used to determine the statistical significance in the case of nonparametric analysis. The level of significance was set at $p \leq 0.05$. For TEM analysis and to avoid bias, blind g-ratio measurements of the sham, TMEV mice, and UCM03025-treated TMEV mice were performed. Differences between g-ratios of the three experimental groups were analyzed using the Kruskal-Wallis one-way ANOVA; pairwise multiple comparisons were done using the Dunn's method. A statistical software package (GraphPad Prism 5; GraphPad Software; RRID: SCR_002798) was used to analyze and display the number of axons and g-ratios.

\section{Results}

Astrogliosis is associated with accumulation of CSPGs in demyelinated spinal cord lesions at chronic phases of TMEV-IDD

Changes in CSPGs accumulation occur in TMEV-IDD (Haist et al., 2012; Feliu et al., 2015), but specific CSPGs accumulation in demyelinated lesions at the chronic phase of the disease remains unknown. As such, we evaluated astrogliosis in the spinal cord of infected mice at 85 (motor dysfunction evaluation) and 105 (to study remyelination) dpi through GFAP and vimentin staining, this last one as an indicator of reactive astrocytes (Nash et al., 2011). CSPGs were analyzed by RT-PCR, immunohistochemistry using the CS-56 antibody, and by Western blot. Finally, to determine whether CSPGs accumulation coincides with demyelinated lesions, we used MBP staining. GFAP staining increased at 85 dpi (Fig. $1 A, D ; p=0.003$ ) showing a tendency to increase at 105 dpi. Vimentin and CS-56 augmented at both 85 (vimentin, $p=0.010$; CS-56, $p=0.013$ ) and $105 \mathrm{dpi}$ (vimentin, $p=0.016$; CS-56, $p=0.048$ ) in demyelinated areas identified by MBP staining (Fig. $1 A, D, E$ ). The cells in which CS-56 expression was upregulated in the spinal cord of TMEV mice were identified as astrocytes $\left(\mathrm{GFAP}^{+}\right.$or vimentin $\left.{ }^{+}\right)$not microglial cells $\left(\mathrm{Iba}-1^{-}\right)$ (Fig. 1B,C). The expression of the CSPGs genes brevican and phosphacan was upregulated at 85 (brevican, $p=0.000$; phosphacan, $p=0.001$ ) and $105 \mathrm{dpi}$ (brevican, $p=0.001$; phosphacan, $p=0.007$ ), whereas neurocan was only higher than sham mice at $105 \mathrm{dpi}(p=0.000)$ (Fig. $1 F)$. Western blots of CSPGs proteins showed that neurocan, brevican, and phosphacan were not significantly upregulated when evaluated independently but reached significance at $85 \mathrm{dpi}$ when they were analyzed together in a joint manner (Fig. $1 G ; p=0.033$ ), as it was also seen by immunochemistry using CS-56 antibody.

\section{The blockade of CSPGs synthesis by xyloside treatment improves motor function in TMEV-infected mice}

Next, we studied the impact of the blockade of CSPGs synthesis on the motor deficits of TMEV-infected mice. When administering xyloside, an inhibitor of CSPGs production $(2.4 \mathrm{mg} /$ animal/ day, i.p.) for 10 consecutive days once the symptomatology was established, TMEV mice showed ameliorated both horizontal and vertical motor deficits at 85 dpi [Figure $2 A$ (HACTV, $p=$ 0.013 TMEV vs SHAM; $p=0.000$ TMEV-XIL vs TMEV; VACTV, $p=0.003$ TMEV vs SHAM; $p=0.007$ TMEV-XIL vs TMEV) $]$. The improvement of motor function by xyloside matches to reduced astrogliosis, particularly to vimentin staining (Fig. $2 B, C$; $p=0.04$ ), and to reduced total CSPGs as assessed by immunohistochemistry labeling with CS-56 antibody in the spinal cord of infected animals (Fig. $2 B, C ; p=0.017$ ). When we analyzed neurocan, phosphacan, and brevican at protein level by Western blot, both neurocan $(p=0.016)$ and brevican $(p=0.036)$ were diminished in xyloside-TMEV mice with no significant differences in phosphacan. A reduced CSPGs total protein $(p=0.013)$ was also observed in TMEV-xyloside mice when analyzed in a joint manner (Fig. 2D), confirming that xyloside reduces the CSPGs burden in TMEV-IDD.

\section{2-AG hydrolysis inhibition recovers motor function in TMEV mice through $\mathrm{CB} 1$ and $\mathrm{CB} 2$ receptors and dampens astrogliosis and CSPGs deposition}

We used a potent reversible MAGL inhibitor (UCM03025) with pronounced activity in vivo (Hernández-Torres et al., 2014) that has been shown to increase 2-AG levels in the spinal cord and to diminish clinical symptoms in the experimental autoimmune encephalomyelitis (EAE) MS model. When administered for 10 consecutive days (i.p.), $5 \mathrm{mg} / \mathrm{kg}$, once the symptomatology was established, UCM03025 ameliorated both horizontal and vertical motor deficits of TMEV-infected mice analyzed in the activity cage at 85 dpi [Figure $3 A$ (HACTV, $p=0.000$ TMEV vs SHAM; $p=0.001$ TMEV-UCM vs TMEV; VACTV, $p=0.000$ TMEV vs SHAM; $p=0.000$ TMEV-UCM vs TMEV)]. To determine the receptors involved in the effects of UCM03025, we administered selective CB1 (AM251) and CB2 (AM630) receptor antagonists. The motor function improvement elicited by UCM03025 was reverted significantly by the $\mathrm{CB} 1$ or $\mathrm{CB} 2$ receptor antagonists when administered individually or together [Fig. 3A (HACTV, $\operatorname{AM} 251 p=0.007 ; \operatorname{AM} 630 p=0.015 ; \operatorname{AM} 251-\operatorname{AM} 630 p=0.050$; VACTV, AM251 $p=0.016$; AM630 $p=0.014$; AM251-AM630 $p=0.004)]$. In support of the results with the inhibitor of MAGL, direct intraventricular infusion of 2-AG $(5 \mathrm{mg} / \mathrm{kg}, 0.26 \mu \mathrm{l} / \mathrm{h})$ through the implantation of miniosmotic pumps also attenuated the severity of the disease (Fig. 3B; HACTV, $p=0.004$; VACTV, $p=0.012$ ). We next tested whether UCM03025 reduces astrogliosis and the content of CSPGs in the spinal cord of TMEV mice at $85 \mathrm{dpi}$. We found a significant reduction of astrogliosis (Fig. $3 C, D$; GFAP; $p=0.025$; vimentin: $p=0.050$ ), and of total CSPGs assessed by immunohistochemistry (Fig. $3 C, D$; CS-56 $p=0.023)$. Phosphacan was diminished at mRNA ( $p=$ $0.000)$ and protein level $(p=0.018)$ (Fig. $3 F, G)$, whereas brevican and neurocan gene expression remained unchanged. A statistical significant reduction was also observed when analyzed CSPGs protein levels in a joint manner were compared with TMEV mice without UCM03025 treatment (Fig. 3G; $p=0.009$ ). 

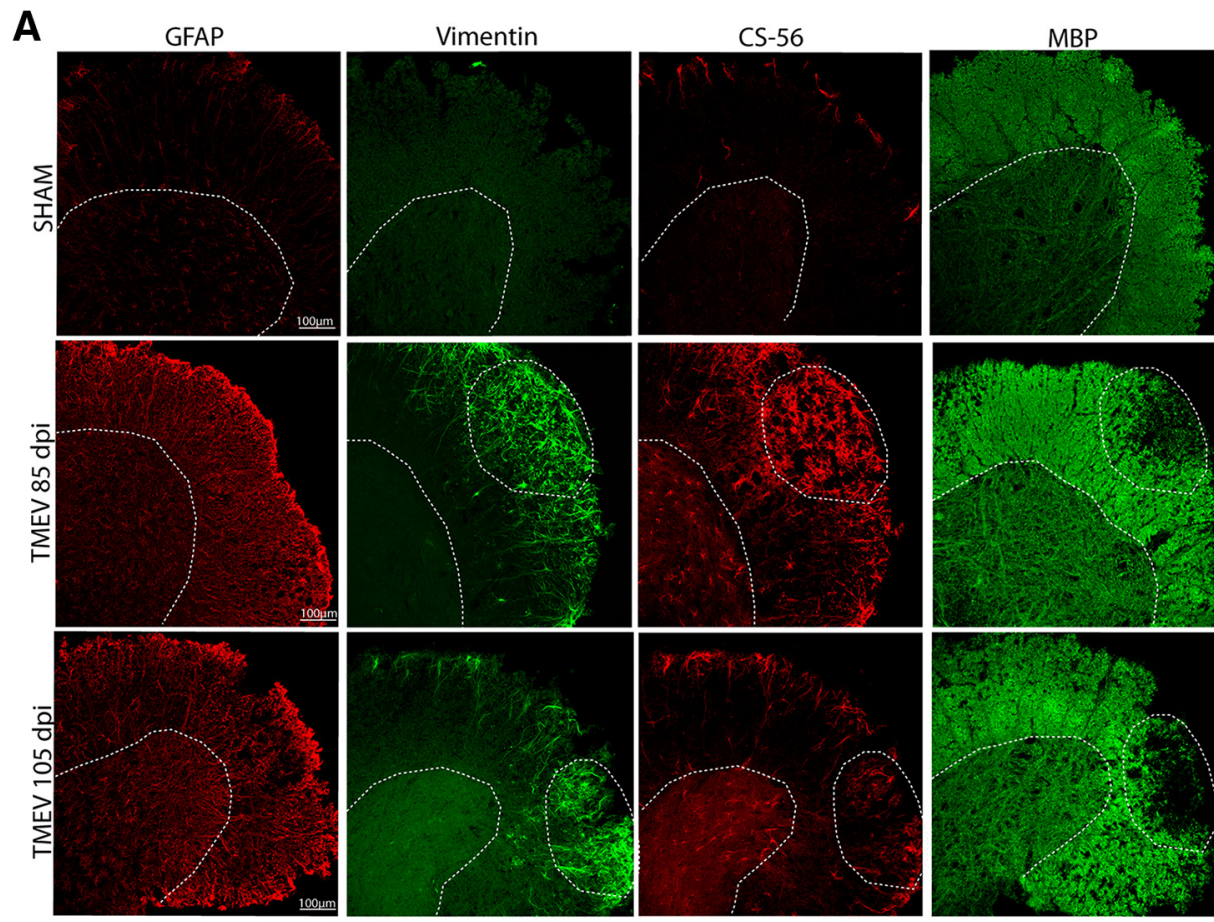
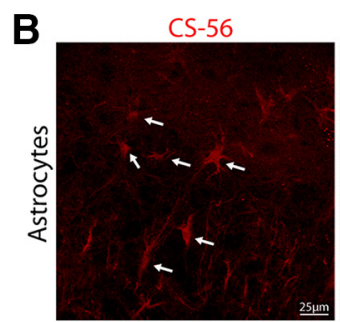

GFAP/CS-56/DAPI
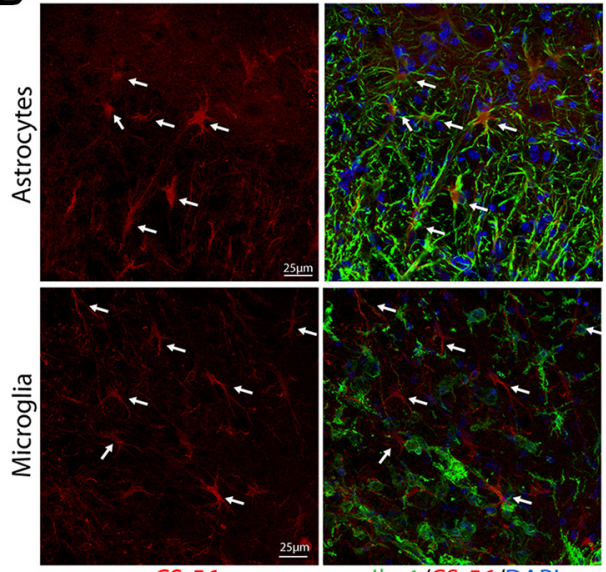

CS-56

D

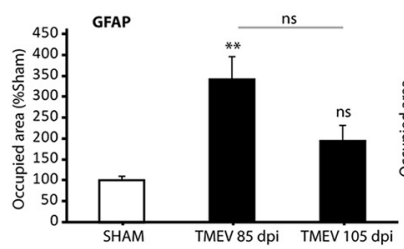

$\mathbf{F}$

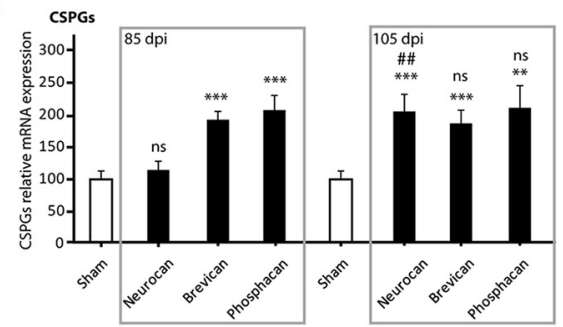

C

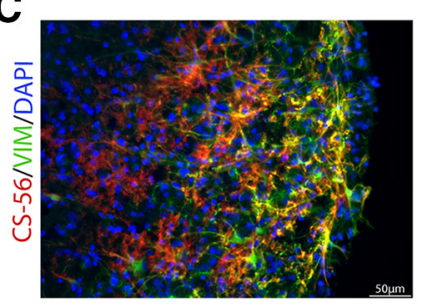

E

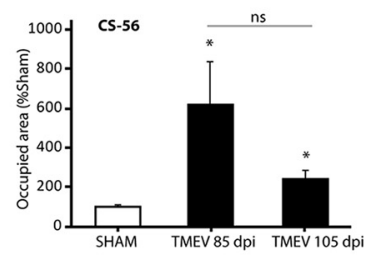

G

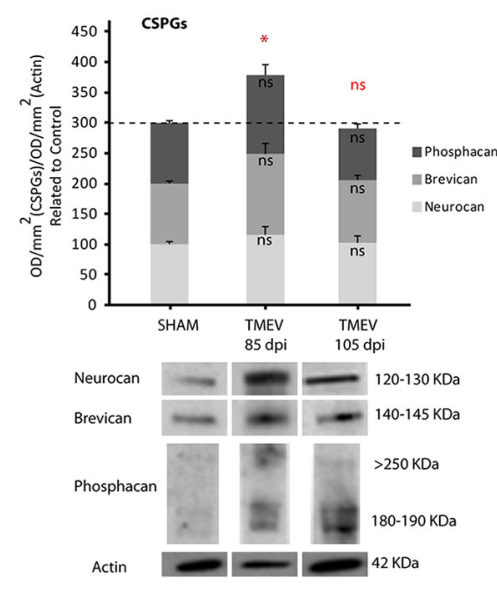

Figure 1. Astrogliosis is associated with CSPGs accumulation and demyelination in the mouse spinal cord at chronic phases of TMEV infection. Representative microphotographs of spinal cord sections stained for astrocytes (GFAP and vimentin), CSPGs (CS-56), and myelin (MBP) at 85 and $105 \mathrm{dpi}(\boldsymbol{A})$. CS-56-expressing cells were astrocytes (GFAP ${ }^{+}$, vimentin ${ }^{+}$) and did not colocalize with microglial cells (lba- $\left.{ }^{-}\right)(\boldsymbol{B}, \boldsymbol{C})$. Astrogliosis is evident in TMEV-infected mice (GFAP and vimentin staining) $(\boldsymbol{D})$ and is accompanied by increased (S-56 staining (E), and by gene expression of neurocan, brevican, and phosphacan $(\boldsymbol{F})$. CSPGs analyzed together in a joint manner by Western blot revealed an increment of these molecules at 85 dpi (G). Data indicate mean \pm SEM. ${ }^{* * *} p \leq$ 0.001 versus sham. ${ }^{* *} p \leq 0.01$ versus sham. ${ }^{*} p \leq 0.05$ versus sham. ${ }^{\# \#} p \leq 0.01$ versus TMEV 85 dpi. Red statistical significances correspond to comparisons (Figure legend continues.) 
Inhibition of 2-AG hydrolysis increases the number of mature CC1 oligodendrocytes and myelin markers in the spinal cord of TMEV-infected mice

To assess whether UCM03025 treatment modifies the number of OPCs that might migrate to the lesion site in the spinal cord, we analyzed the number of oligodendrocyte progenitor cells (Olig- $2^{+} \mathrm{CC} 1^{-}$) and mature oligodendrocytes $\left(\mathrm{CCl}^{+}\right)$and the expression of different transcription factors expressed by OPCs (Olig-2 and $\mathrm{Nkx} 2.2)$. To determine OPC proliferation, $\mathrm{BrdU}(50 \mathrm{mg} / \mathrm{kg}$ ) was administered daily for $10 \mathrm{~d}$ together with UCM03025, or the vehicle alone, before death at $85 \mathrm{dpi}$. The $\mathrm{OPC}$ number (Olig- $\left.2^{+} \mathrm{CC}{ }^{-}\right)$was increased in TMEV mice that received UCM03025 (Fig. 4A, $B ; p=$ 0.044). In addition, the $\mathrm{BrdU}{ }^{+} \mathrm{OPC}$ number (Olig- $2{ }^{+} \mathrm{BrdU}{ }^{+}$cells) increased in UCM03025-treated TMEV mice compared with sham mice (Fig. $4 A, B ; p=0.028$ TMEV vs SHAM; $p=0.002$ TMEV UCM vs TMEV). Decreased Nkx2.2 expression in TMEV mice at $85 \mathrm{dpi}(p=0.039)$ was counteracted by UCM03025 treatment $(p=0.008)$ that also upregulated Olig-2 mRNA expression ( $p=0.005$ ) (Fig. $4 C$ ). Most importantly, UCM03025 augmented the number of $\mathrm{CC}^{+}{ }^{+}$mature oligodendrocytes (Fig. $4 D ; p=0.021$ ) leading to restoration of MBP loss to sham levels evaluated by Western blot (Fig. $4 E ; p=0.021$ TMEV vs SHAM; $p=0.006 \mathrm{TMEV}$ UCM vs TMEV). These results suggest that UCM03025 could enhance the endogenous mechanism by which proliferating OPCs migrate to the lesion site and differentiate to mature myelinating oligodendrocytes.

\section{Inhibition of 2-AG hydrolysis attenuates spinal cord inflammation in TMEV-infected mice}

To study whether UCM03025 is able to target neuroinflammation as it does in the experimental model of EAE (HernándezTorres et al., 2014), we analyzed the leukocyte infiltration, microglia staining, and the expression of different inflammatory mediators in the spinal cord of infected animals. TMEV mice showed infiltration of immune cells into the spinal cord at $85 \mathrm{dpi}$ that was reduced by UCM03025 as shown by hematoxilin-eosin staining (Fig. $5 A ; p=$ 0.000 TMEV vs SHAM; $p=0.001$ TMEV UCM vs SHAM). Because innate immune response in the CNS is important for the maintenance of progression of TMEV-IDD and microglia provide the first line of defense against TMEV, we analyzed the effect of UCM03025 on Iba-1 immunoreactivity. Iba-1 staining showed a significant increase in the spinal cord of TMEV mice compared with the control sham mice $(p=0.039)$, and this effect was reversed following UCM03025 administration $(p=0.019)$ (Fig. 5B).

Indeed, decreased microglia activation was accompanied by a significant reduction of IL- $1 \beta$ mRNA levels (Fig. $5 C$; $p=0.004$ TMEV vs SHAM; $p=0.026$ TMEV UCM vs TMEV), a tendency to reduce TNF $\alpha$ and NOS-II [Figure 5C (TNF $\alpha p=0.002 \mathrm{TMEV}$ vs SHAM; $p=0.133$ TMEV UCM vs TMEV; NOS-II $p=0.007$ TMEV vs SHAM; $p=0.078$ TMEV UCM vs TMEV)] and to upregulate the Arg-1 mRNA expression (Fig. $5 C ; p=0.179$ ). These data suggest that UCM03025 could diminish neuroinflammation in TMEV mice.

\section{$\leftarrow$}

(Figure legend continued.) between joint CSPGs analysis. Nonparametric Kruskal-Wallis test for vimentin, CS-56 staining, and phosphacan RT-PCR analysis (one-way ANOVA followed by Tukey's and Bonferroni's test for GFAP staining, neurocan, brevican RT-PCR analysis, and CSPGs Western blot analysis). Five to 8 mice per group were used for histological analysis. Eight to 11 animals per group were used for mRNA expression analysis. Eight to 11 per group were used for Western blot analysis. Scale bar, $100 \mu \mathrm{m}, 50 \mu \mathrm{m}, 25 \mu \mathrm{m}$. Dotted lines indicate spinal cord gray matter and demyelinated areas. Arrows point to microglia and astrocytes.

\section{2-AG hydrolysis inhibition drives long-term changes in CSPGs deposition and improves motor disability}

To assess whether the increment of progenitors and mature oligodendrocytes observed in the demyelinated spinal cord at $85 \mathrm{dpi}$ leads to effective remyelination, we maintained TMEV mice treated with UCM03025 until 105 dpi without further treatment. Cessation of treatment did not modify the motor improvement displayed by the UCM03025-treated mice at $85 \mathrm{dpi}$, as animals still showed functional motor recovery at 105 dpi (Fig. 6A; HACTV, $p=0.001$ TMEV vs SHAM; $p=0.003$ TMEV-UCM vs TMEV; VACTV, $p=0.000$ TMEV vs SHAM; $p=0.024$ TMEV-UCM vs TMEV). The diminished gene expression of phosphacan by UCM03025 treatment also persisted at $105 \mathrm{dpi}(p=0.004)$ together with a downregulation of neurocan $(p=0.002)$ (Fig. $6 B$ ), and no changes in brevican coupled to the overall reduced levels of CS-56 staining in the spinal cord of TMEV mice $(p=0.017)$ (Fig. $6 C$ ). The analysis of specific CSPGs protein expression revealed that phosphacan persisted diminished $(p=0.001)$, brevican was reduced ( $p=0.014$ ), and neurocan did not change (Fig. $6 D)$ at 105 dpi. The joint analysis of CSPGs indicated that UCM03025 elicited a long-term reduced deposition in the spinal cord of TMEV mice compared with TMEV mice that received vehicle ( $p=0.007)$. The axonal integrity was preserved $20 \mathrm{~d}$ after stopping UCM03025 treatment as it is showed by neurofilament- $\mathrm{H}$ staining analysis (Fig. $6 E ; p=0.000$ TMEV vs SHAM; $p=0.029$ TMEV UCM vs TMEV) and the anterograde BDA tracing from the corticospinal tract in the spinal cord of TMEV mice (Fig. $6 F$ ). Finally, when spinal cord sections were analyzed by TEM, it was evident that UCM03025 treatment enhanced remyelination at $105 \mathrm{dpi}$ (Fig. 7), as shown in the TEM images with the presence of abundant newly formed thin myelin sheaths (Fig. 7A). In addition, an increase in myelinated axons was observed in UCM03025 (899 of 1000 axons) versus TMEV-infected mice (417 of 1000 axons) ( $p=0.000$; Fig. $7 B$ ). Furthermore, the g-ratios of myelinated axons were significantly higher in UCM03025-treated TMEV mice $(0.82 \pm 0.0018)$ than in sham $(0.77 \pm 0.0024 ; p=$ $0.000)$ and TMEV mice $(0.79 \pm 0.0019 ; p=0.000)$ (Fig. $7 C)$. This suggests that axons with a g-ratio $>0.8$ were likely remyelinated, as higher g-ratio corresponds to thinner myelin sheaths (Mei et al., 2016). Together, these results indicate the importance of an elevated tone of 2-AG for endogenous reparative mechanisms in a model of progressive MS.

\section{Discussion}

When the CNS is subjected to chronic demyelination, as occurs in MS, CSPGs are strongly upregulated and they form part of the astrogliotic scar that impairs axonal regeneration and remyelination (Siebert and Osterhout, 2011; Lau et al., 2012). CSPGs inhibit the differentiation of OPCs (Siebert and Osterhout, 2011; Lau et al., 2012; Pendleton et al., 2013) and impede neuron growth cone extension in culture (Zhou et al., 2014; Dyck et al., 2015; Lang et al., 2015). Therefore, a reduction in CSPGs deposition constitutes a rational therapeutic approach in chronic progressive demyelinating diseases. In vitro studies show that the endocannabinoid 2-AG facilitates the survival and differentiation of oligodendrocytes (Gómez et al., 2010, 2011) and increases OPC proliferation (Gómez et al., 2015). Here, by using a reversible inhibitor of MAGL, we reveal a novel role of 2-AG, the suppression of CSPGs barrier to thereby promote remyelination and functional motor recovery in TMEV mice. TMEV-IDD is a suitable model to study whether CSPGs influence remyelination as it involves progressive axonal loss and neurological dysfunction similar to progressive forms of MS. Spontaneous remyelination 
A
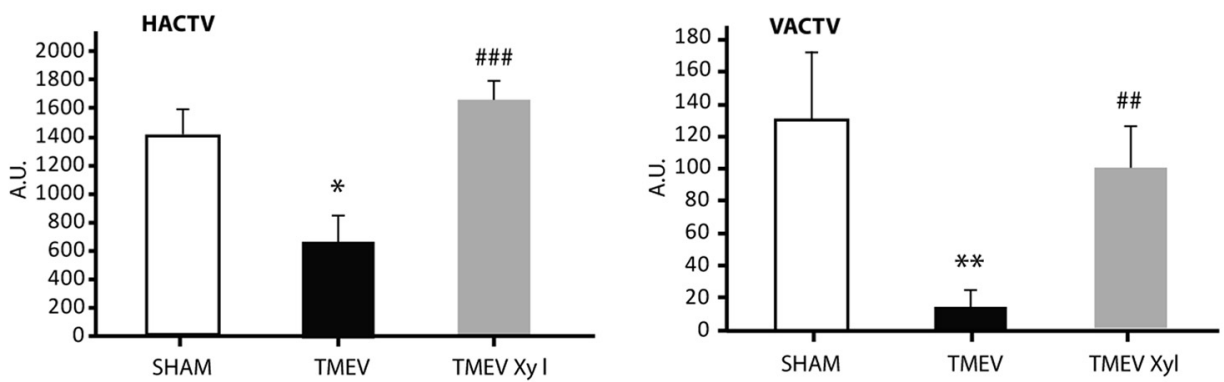

B
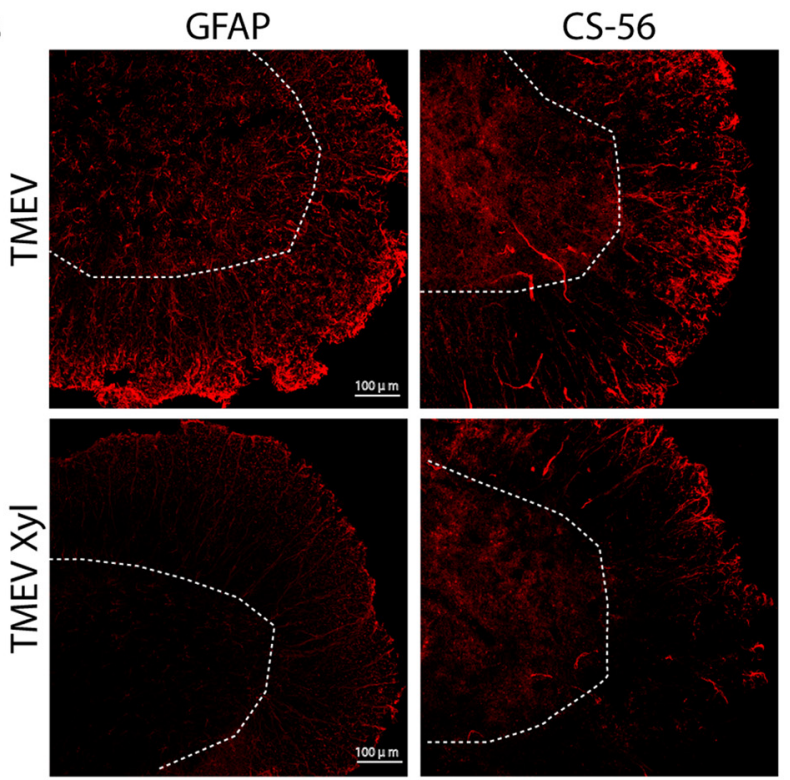

D
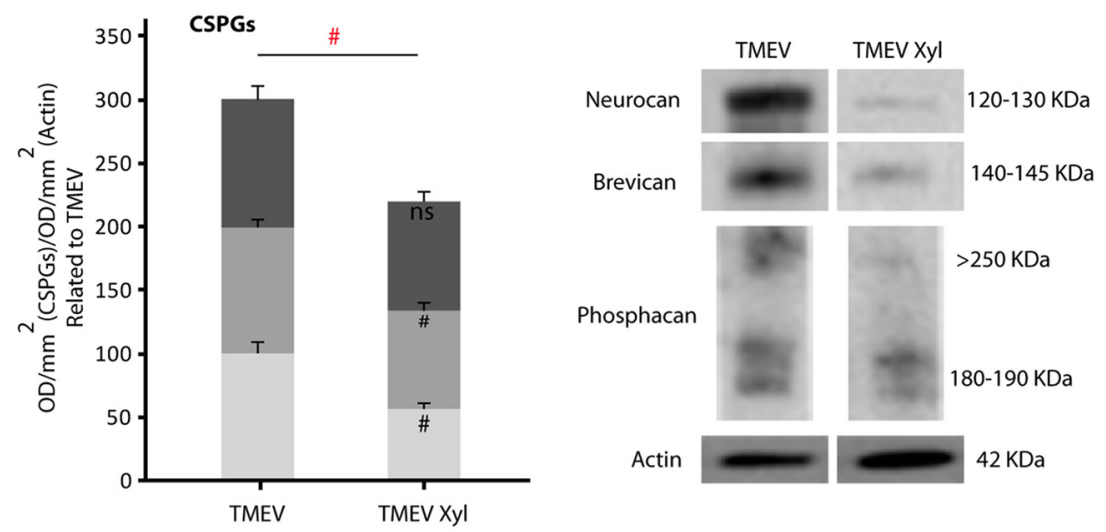

C
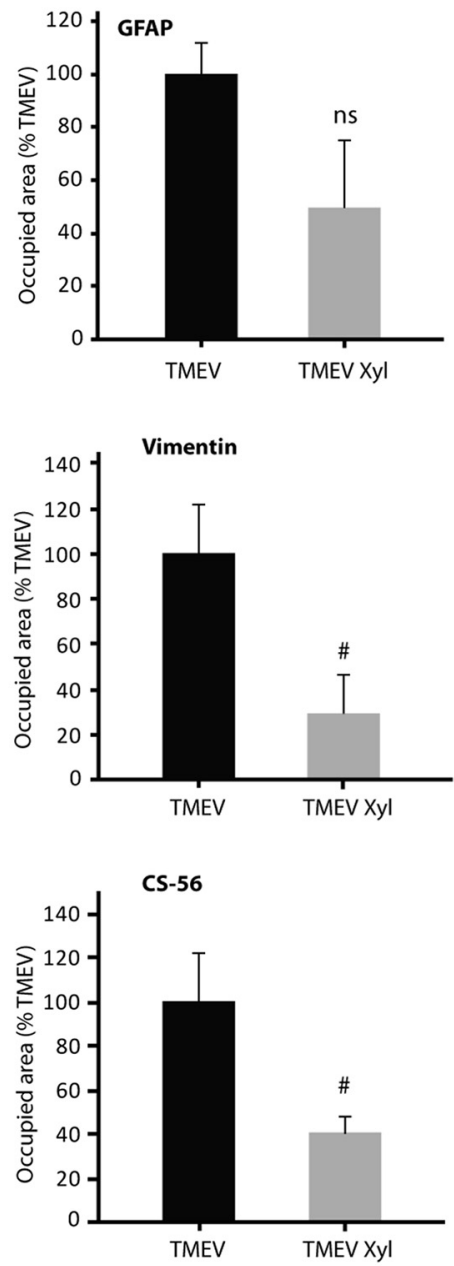

Neurocan Brevican $\square$ Phosphacan

Figure 2. CSPGs synthesis inhibition by xyloside treatment improves motor function in TMEV-IDD mice. Motor activity analysis at 85 dpi, showing a significant attenuation of motor deficits following xyloside treatment $(\boldsymbol{A})$. Xyloside decreased astrogliosis in the spinal cord of TMEV-IDD mice (GFAP and vimentin staining) and diminished (SS-56 staining (B, $\boldsymbol{C}$ ). CSPGs evaluation by Western blot revealed a diminution of both neurocan and brevican and a reduction of CSPGs evaluated together in a joint manner (D). Data indicate mean \pm SEM. ${ }^{* *} p \leq 0.01$ versus sham. ${ }^{*} p \leq 0.05$ versus sham. ${ }^{\# \# \#} p \leq 0.001$ versus TMEV. ${ }^{\# \#} p \leq 0.01$ versus TMEV. ${ }^{\#} \leq 0.05$ versus TMEV. Red statistical significances correspond to comparisons between joint CSPGs analysis (one-way ANOVA followed by Tukey's and Bonferroni's test for the motor test; unpaired two-tailed Student's $t$ test for GFAP, vimentin, CS-56 staining, brevican, and phosphacan Western blot analysis; nonparametric Mann-Whitney U test for neurocan and (SPGs protein evaluated together in a joint manner). Five or 6 mice per group were used for motor activity. Five or 6 mice per group were used for histological analysis. Five or 6 animals per group were used for mRNA expression analysis. Scale bar, $100 \mu \mathrm{m}$. Dotted lines indicate spinal cord gray matter.

can be observed in a small fraction of lesions (Denic et al., 2014), and recent studies have shown that CSPGs are upregulated in this model (Haist et al., 2012; Feliu et al., 2015).

The analysis of CSPGs at chronic phases of TMEV-IDD using the CS-56 antibody indicates that they are overexpressed in the spinal cord of TMEV mice as it has been described in other experimental demyelinating conditions reported previously (Lau et al., 2012; Keough et al., 2016). Indeed, the accumulation of CSPGs observed in our study was clearly associated with demyelinated lesions. CSPGs upregulation was accompanied by strong astrogliosis be- 
A

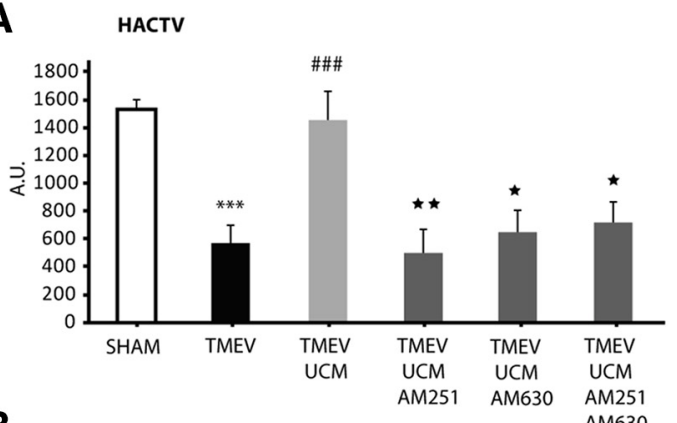

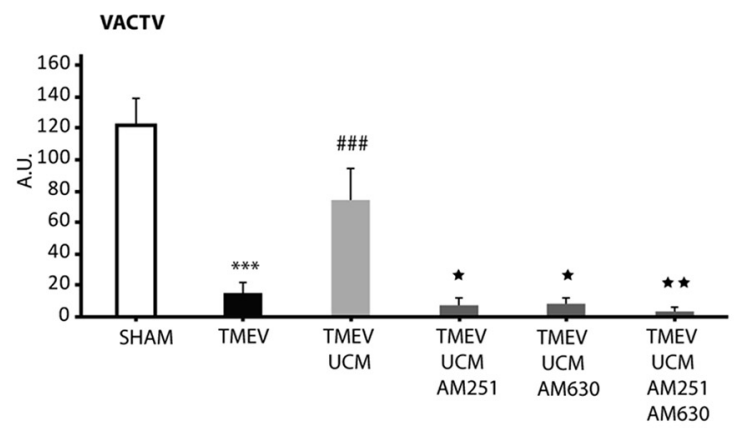

B

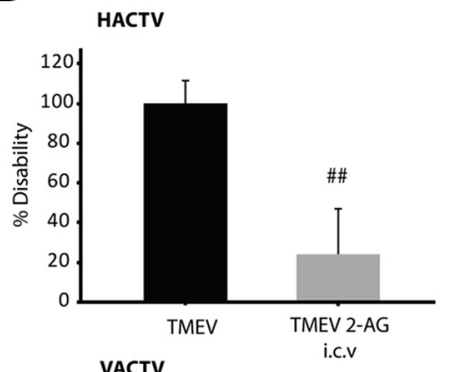

C GFAP
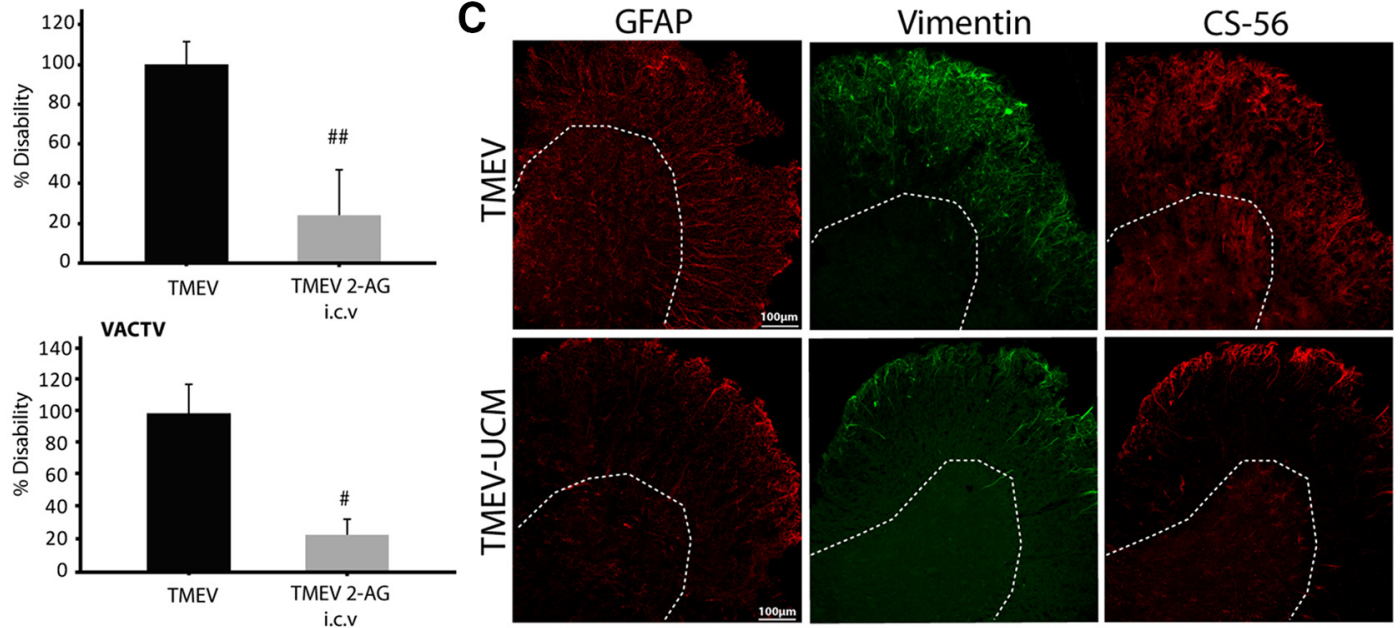

D
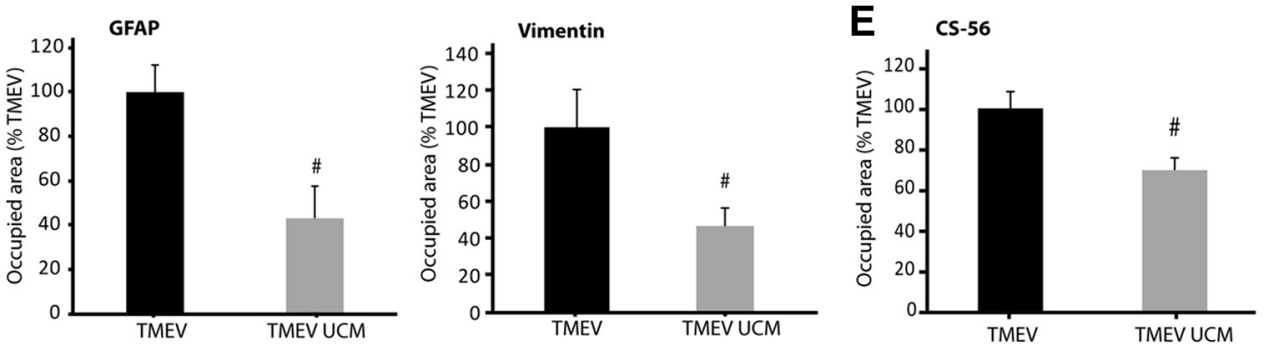

$\mathbf{F}$

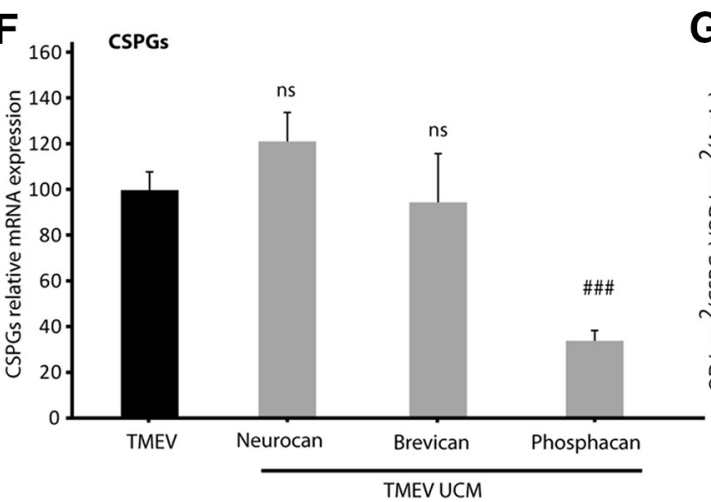

G

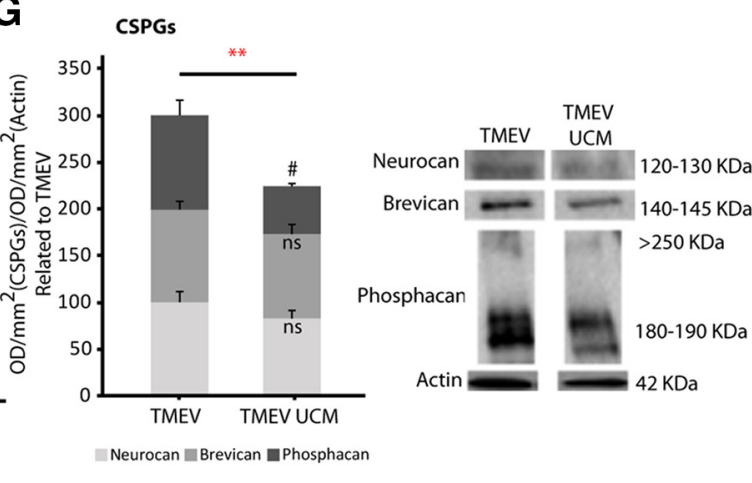

Figure 3. The inhibition of 2-AG hydrolysis improves motor function in TMEV-IDD mice by activating CB1 and CB2 receptors, thereby reducing astrogliosis and CSPGs deposition. A significant attenuation of the motor deficits at 85 dpi was observed following UCM03025 treatment and reversed by CB1 and CB2 antagonists $(A)$. Intracerebroventricular administration of 2-AG by miniosmotic pumps slowed motor disability monitorized by the HACTV and VACTV (B). UCM03025 treatment reduced spinal cord astrogliosis (GFAP and vimentin staining) and CS-56 staining (C, $\boldsymbol{E}$ ) and phosphacan mRNA expression with no effects in neurocan and brevican $(\boldsymbol{F})$. CSPGs evaluation by Western blot revealed a significant diminution of phosphacan with no significance in neurocan and brevican. CSPGs reduction evaluated together in a joint manner was also seen following UCM03025 treatment (G). Data are mean \pm SEM. ${ }^{* * *} p \leq 0.001$ versus sham. ${ }^{* *} p \leq 0.001$ versus TMEV. ${ }^{\# \#} p \leq 0.01$ versus TMEV. ${ }^{*} p \leq 0.05$ versus TMEV. ${ }^{\star \star} p \leq 0.01$ versus TMEV UCM. ${ }^{\star} p \leq 0.05$ versus TMEV UCM. Red statistical significances correspond to comparisons between joint CSPGs analysis (nonparametric Kruskal-Wallis test for the motor test; unpaired two-tailed Student's $t$ test for GFAP, vimentin, CS-56 staining, neurocan, phosphacan RT-PCR analysis, neurocan and CSPGs, Western blot evaluated together in a joint manner and 2-AG intracerebroventricular motor evaluation; nonparametric Mann-Whitney $U$ test for brevican RT-PCR analysis and phosphacan Western blot analysis). Five or 6 mice were used for motor activity analysis (two independent experiments). Five or 6 animals were used in the case of antagonist-treated animals. Five or 6 mice per group were used for histological analysis. Five or 6 animals per group were used for mRNA expression analysis. Five or 6 animals per group were used for Western blot analysis. Scale bar, $100 \mu \mathrm{m}$. Dotted lines indicate spinal cord gray matter. 


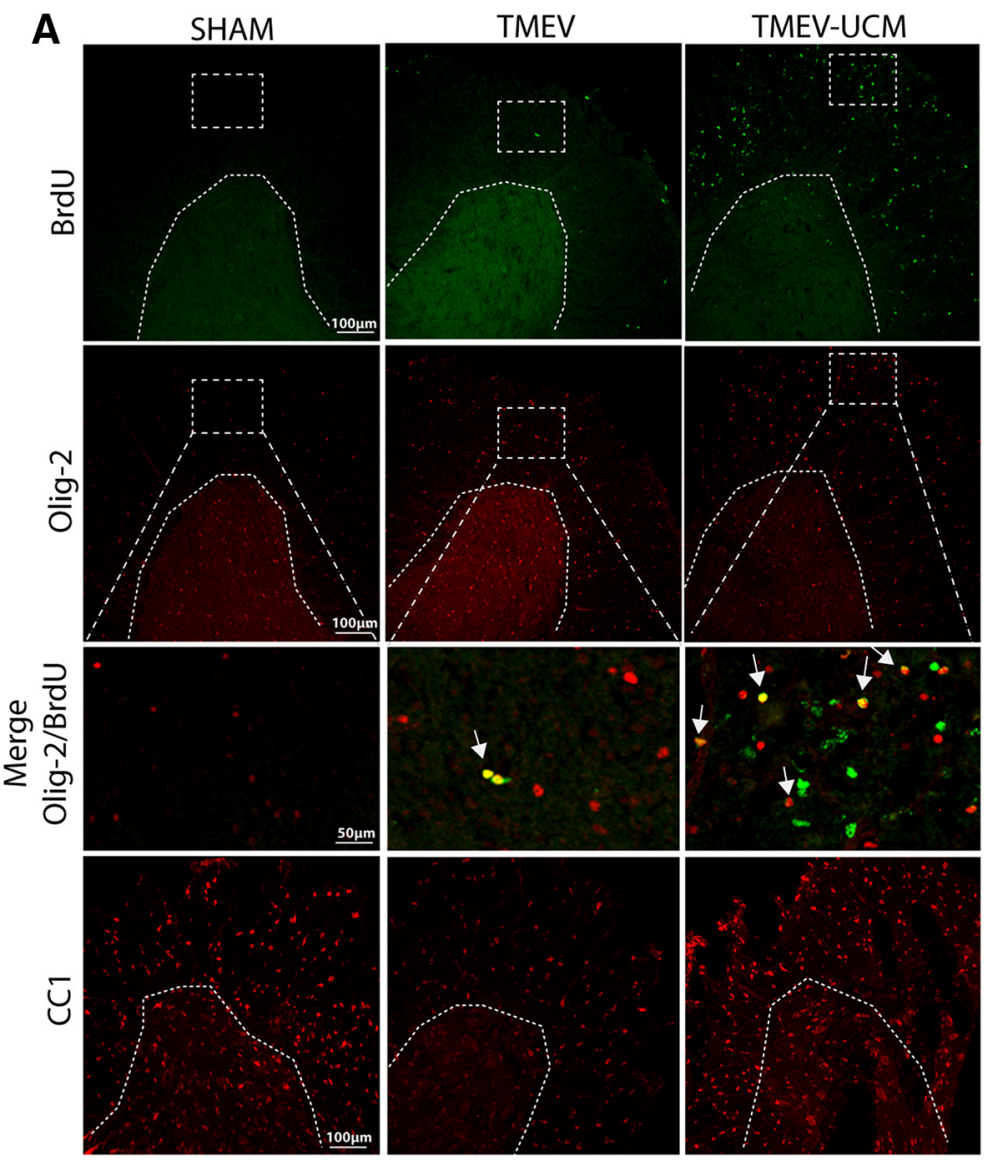

B

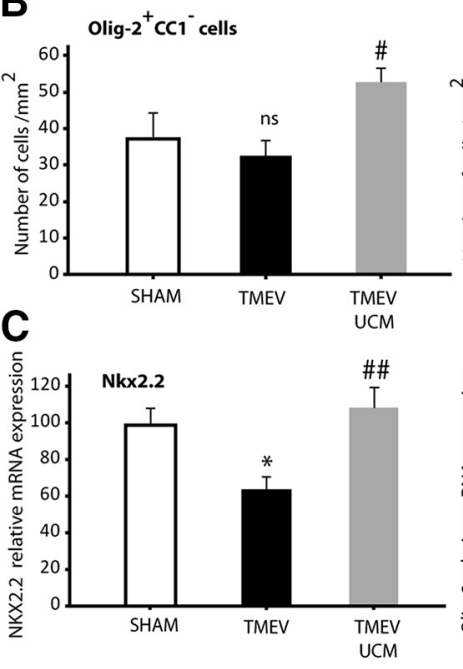

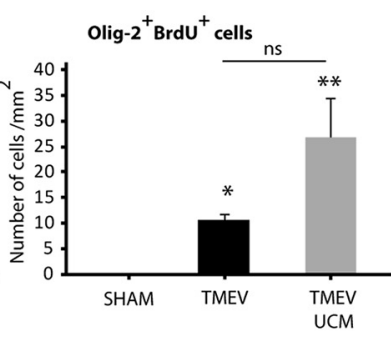

Olig-2

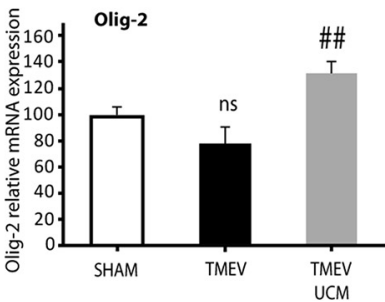

D
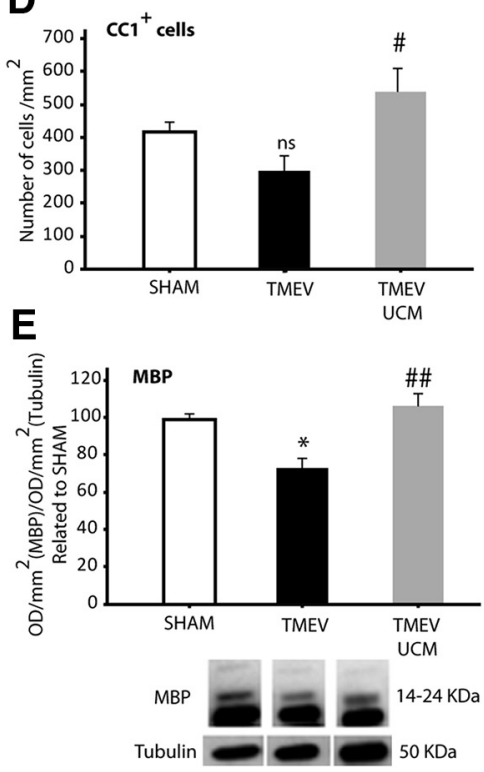

Figure 4. UCM03025 increased the expression of OPC markers, Olig-2 ${ }^{+}$proliferative cells, mature $\mathrm{CC}^{+}{ }^{+}$oligodendrocytes, and myelin markers in the spinal cord of TMEV-infected mice. Representative microphotographs of cervical spinal cord sections obtained at $85 \mathrm{dpi}$ and stained for BrdU, OPCs (0lig-2), and mature oligodendrocytes (CC1) $(\boldsymbol{A})$. UCM03025 increased the number of Olig- $2^{+} / \mathrm{CC}^{-}$-labeled cells and tended to increase their proliferation (0lig- $2^{+} / \mathrm{BrdU}^{+}$(ells) (B). UCM03025 significantly increased gene expression of $0 \mathrm{PC}$ markers (0lig-2 and Nkx2.2) $\left(\boldsymbol{C}\right.$, augmented the number of $\mathrm{CC}^{+}$mature oligodendrocytes $(\boldsymbol{D})$, and MBP analyzed by Western blot $(\boldsymbol{E})$. Data are mean \pm SEM. ${ }^{*} p \leq 0.05$ versus sham; ${ }^{* *} p<0.01$ versus sham. ${ }^{\#} p<0.05$ versus TMEV. ${ }^{\# \#} p<0.01$ versus TMEV. Nonparametric Kruskal-Wallis test for BrdU ${ }^{+/}$Olig- $2^{+}$cell quantification and MBP Western blot analysis;

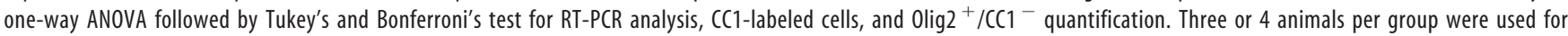
histological analysis. Five or 6 animals per group were used for mRNA expression analysis; 5 or 6 mice per group were used for Western blot analysis. Scale bar, $100 \mu \mathrm{m}, 50 \mu \mathrm{m}$. Dotted lines indicate spinal cord gray matter and amplified areas. Arrows point to 0 lig- $2^{+} / \mathrm{BrdU}^{+}$cells. 

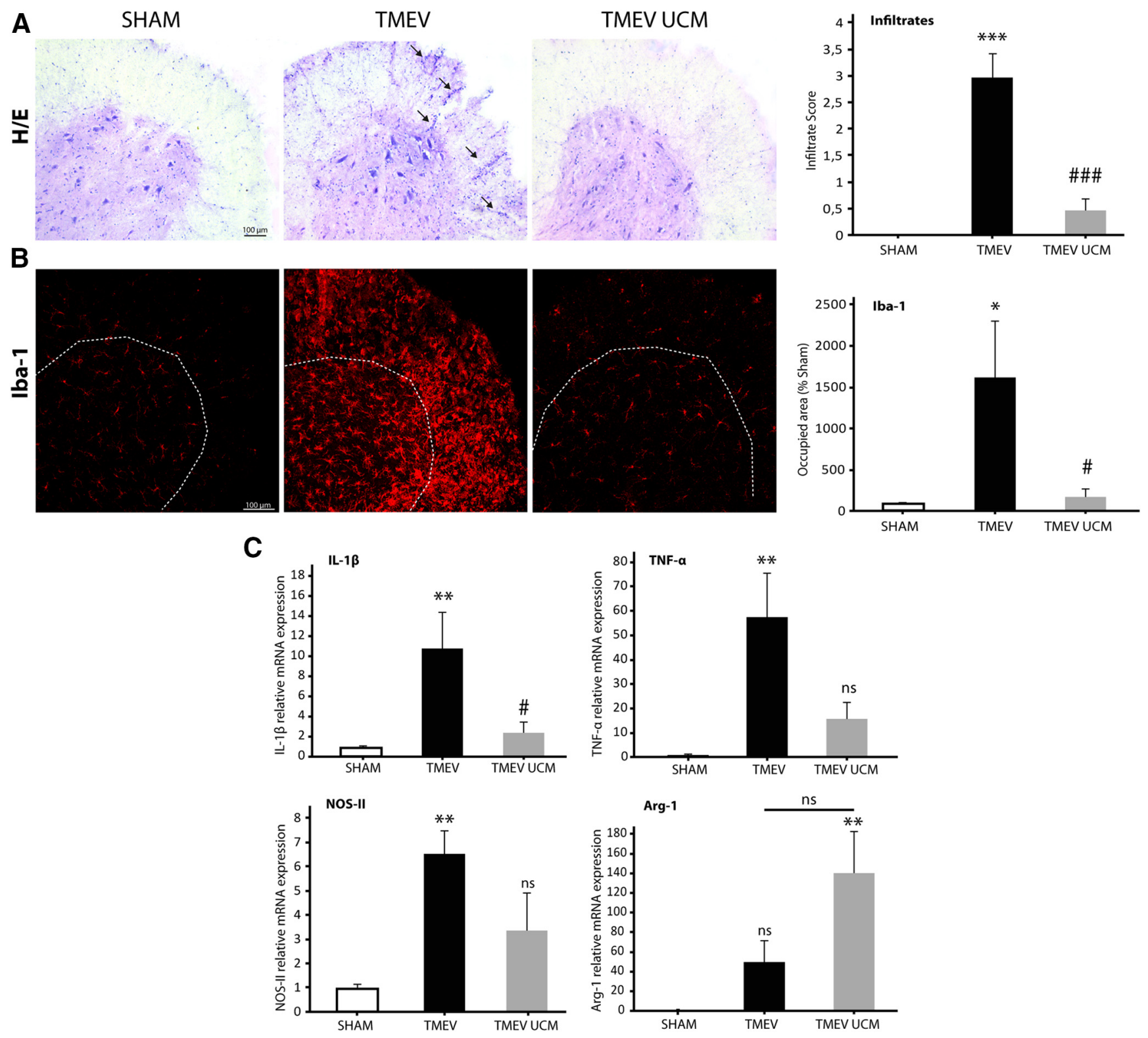

Figure 5. UCM03025 treatment reduced leukocyte infiltration, microglial reactivity, and inflammatory mediators in the spinal cord of TMEV-infected animals. Spinal cord representative microphotographs obtained at $85 \mathrm{dpi}$ and its score quantification for H\&E to evaluate immune infiltration $(\boldsymbol{A})$. The increase in Iba- 1 staining observed in TMEV mice was reversed by UCM03025 treatment (B). UCM03025 significantly decreased IL-1 $\beta$ mRNA expression and showed a tendency to reduce TNF- $\alpha$ and NOS-II and to increase Arg- $1\left(\boldsymbol{C}\right.$. Data are mean \pm SEM. ${ }^{*} p \leq 0.05$ versus sham. ${ }^{* *} p \leq 0.01$ versus sham. ${ }^{* * *} p \leq 0.001$ versus sham. ${ }^{\#} p \leq 0.05$ versus TMEV-VEH animals. ${ }^{\# \#} p \leq 0.001$ versus TMEV-VEH animals. One-way ANOVA followed by Tukey's and Bonferroni's test for H\&E analysis; nonparametric Kruskal-Wallis test for Iba-1 analysis and RT-PCR analysis. Four mice per group were used for histological analysis. Five to 7 per group were used for mRNA analysis. Scale bar, $100 \mu \mathrm{m}$. Dotted lines indicate spinal cord gray matter and amplified areas.

ing the cells labeled by CS-56, vimentin-positive reactive astrocytes, in agreement with the view that astrocytes are the principal source of CSPGs (Hamby and Sofroniew, 2010). Consistent with the CS-56 labeling, we found upregulated expression of specific CSPGs, such as phosphacan, the most consistently overexpressed, neurocan and brevican at mRNA and protein levels. For preventing axonal degeneration, it is relevant to target CSPGs deposition, as suggested by the results of our study where CSPGs clearance by xyloside treatment improves motor function in line with other studies in which xyloside or fluorosamine treatment has been correlated with remyelination in conditions of experimental demyelination and in MS models (Lau et al., 2012; Keough et al., 2016). Even the use of the bacterial enzyme chondroitinase $A B C$ has been very useful in combined strategies to improve spinal cord injury, al- though it requires local injection to the lesion site (Zhao and Fawcett, 2013).

To assess whether the increase of endogenous 2-AG by MAGL inhibition attenuates CSPGs deposition, we used a potent selective and reversible inhibitor, UCM03025 $\left(\mathrm{IC}_{50}=0.18 \mu \mathrm{M}\right)$, which does not induce tolerance after its repeated administration and augments 2-AG levels in the spinal cord (Hernández-Torres et al., 2014). MAGL inactivation diminished astrogliosis and CSPGs accumulation in the spinal cord of TMEV mice, decreasing the gene expression of phosphacan. Importantly, UCM03025 alleviated the motor deficits of diseased mice in a $\mathrm{CB} 1$ and $\mathrm{CB} 2$ receptordependent manner. These findings strongly suggest that the protective effects of MAGL inhibition are consequence of the enhanced 2-AG tone acting on both CB1 and CB2 receptors. 
A

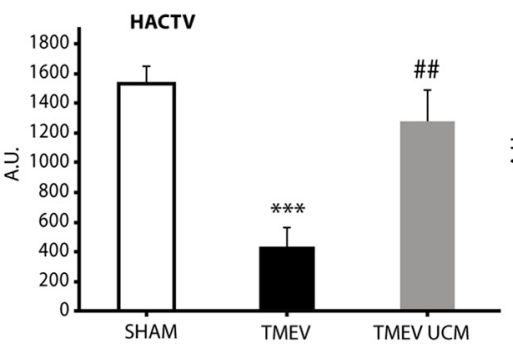

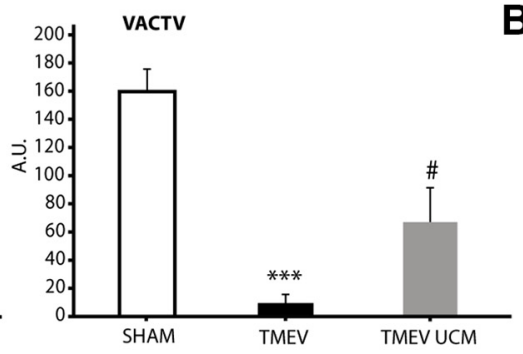

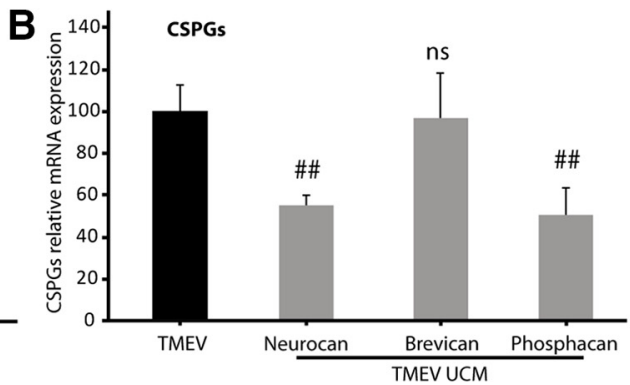

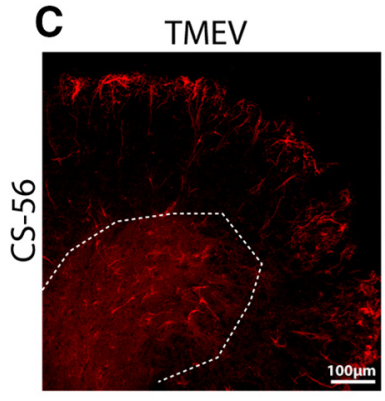

E

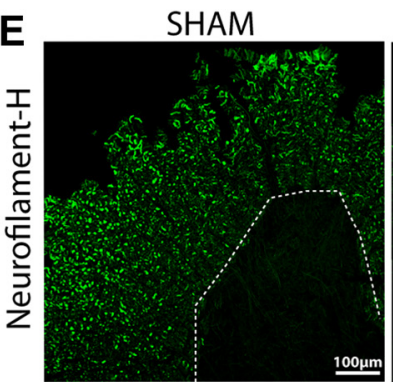

$\mathbf{F}$

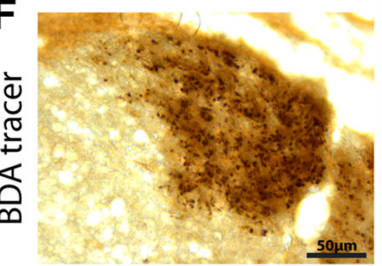

TMEV-UCM

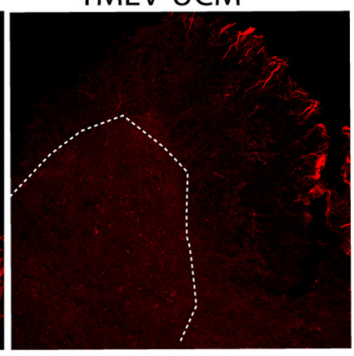

TMEV
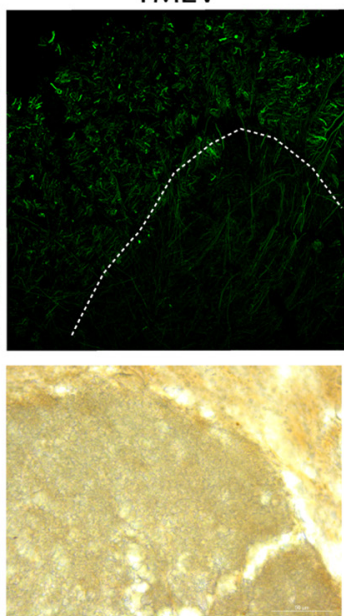

D

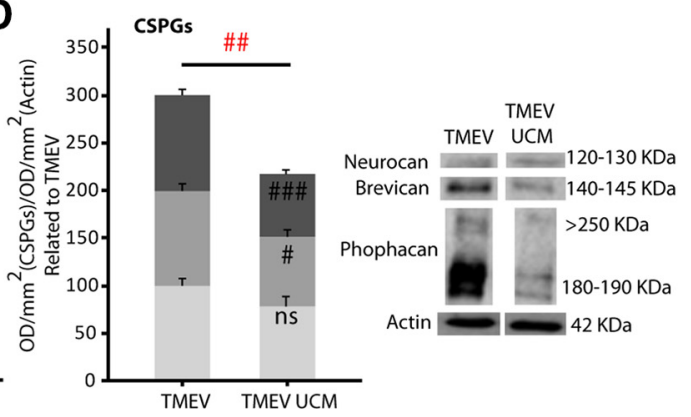
TMEV TMEV TMEV Neurocan $\square$ Brevican $\square$ Phosphacan
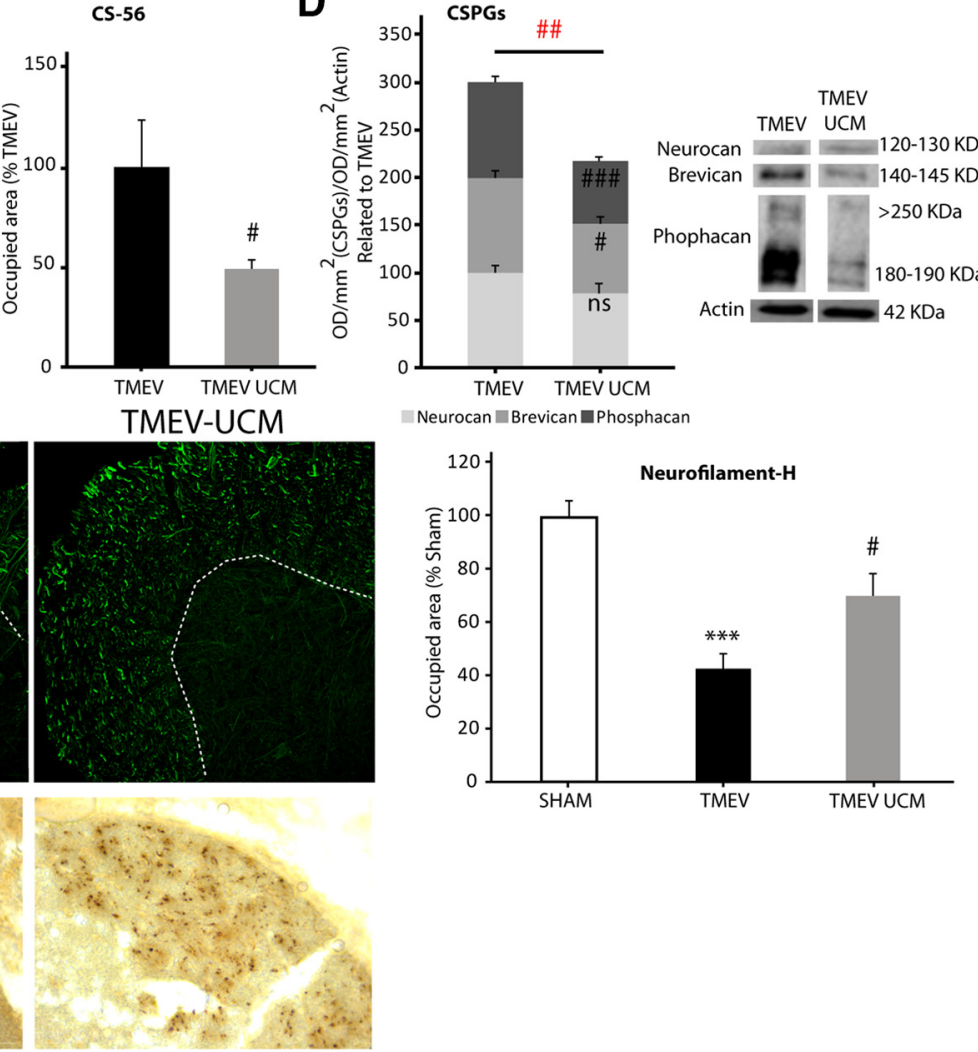

Figure 6. UCM03025 treatment has long-term effects, improving motor disability, diminishing the expression of CSPGs, and reducing axonal loss. Functional motor recovery persisted in mice after the cessation of treatment at $105 \mathrm{dpi}(\boldsymbol{A})$. CSPGs expression was diminished in mice treated with UCM03025, as evident through gene expression of phosphacan and neurocan $(\boldsymbol{B})$, as well as through the area occupied by CS-56 staining (C). CSPGs evaluation by Western blot showed a significant diminution of brevican and phosphacan with no significance in neurocan. CSPGs reduction evaluated together was also seen following UCM03025 treatment (D). UCM03025-treated mice presented less axonal loss, as seen by neurofilament-H staining ( $\boldsymbol{E}$ ), and by the transport of the BDA tracer in the corticospinal tract of the spinal cord $(\boldsymbol{F})$. Data are mean \pm SEM. ${ }^{* * *} p \leq 0.001$ versus sham. ${ }^{\#} p \leq 0.05$ versus TMEV. ${ }^{\# \#} p \leq 0.01$ versus TMEV. ${ }^{\# \# \#} p \leq 0.001$ versus TMEV. Red statistical significances correspond to comparisons between joint CSPGs analysis (one-way ANOVA followed by Tukey's and Bonferroni's test for HACTV activity cage and Neurofilament-H staining analysis; unpaired two-tailed Student's $t$ test for phosphacan RT-PCR and Western blot analysis; nonparametric Mann-Whitney U test for VACTV activity test, neurocan, brevican RT-PCR analysis, and CS-56 staining). Five or 6 mice were used per group and experiment for motor activity analysis (two independent experiments). Five or 6 animals per group were used for histological analysis. Seven or 8 animals per group were used for mRNA expression analysis. Six to 8 animals per group were used for Western blot analysis. Scale bar, $100 \mu \mathrm{m}, 50 \mu \mathrm{m}$. Dotted lines indicate spinal cord gray matter and amplified areas.

The ability of UCM03025 to ameliorate disability in TMEV mice was confirmed when the MAGL substrate, 2-AG, was directly applied to the CNS ventricle through miniosmotic pumps. The involvement of $\mathrm{CB} 1$ and $\mathrm{CB} 2$ receptors in the activity of $2-\mathrm{AG}$ is consistent with previous studies where both receptors need to be activated for 2-AG-induced oligodendrocyte differentiation (Gómez et al., 2010). It is likely that reduced astrogliosis and CSPGs accumulation with the consequent diminished spinal cord axonal degeneration underlies the improved motor performance of TMEV mice treated with UCM03025. Nevertheless, it must be taken into account other actions of 2-AG, such as modulation of CNS inflammation by affecting innate immune response during the progressive phase of the disease.
2-AG administration has therapeutic effects in vivo, such as the reduction of lesion expansion and white matter damage after spinal cord injury (Arévalo-Martin et al., 2010). Indeed, 2-AG ameliorates disability in both the acute and chronic EAE model of MS (Lourbopoulos et al., 2011). The irreversible inhibitor of MAGL, JZL184, decreases the neuroinflammatory response in a model of Alzheimer disease, as well as in adult microglia and astrocyte cell cultures exposed to inflammatory agents (Pihlaja et al., 2015). It is particularly noteworthy that JZL184 suppresses cell death induced by AMPA in oligodendrocyte cultures, reduces inflammation in the EAE model, and preserves myelin integrity in the cuprizone model of demyelination (Bernal-Chico et al., 2015). However, JZL184 blocks MAGL irre- 


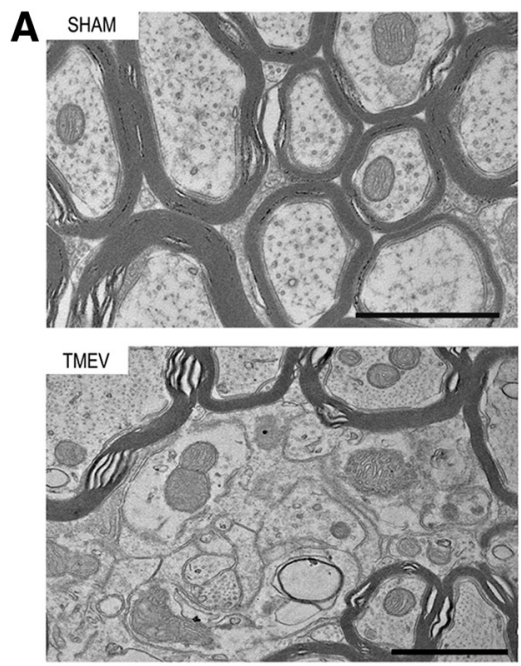

B

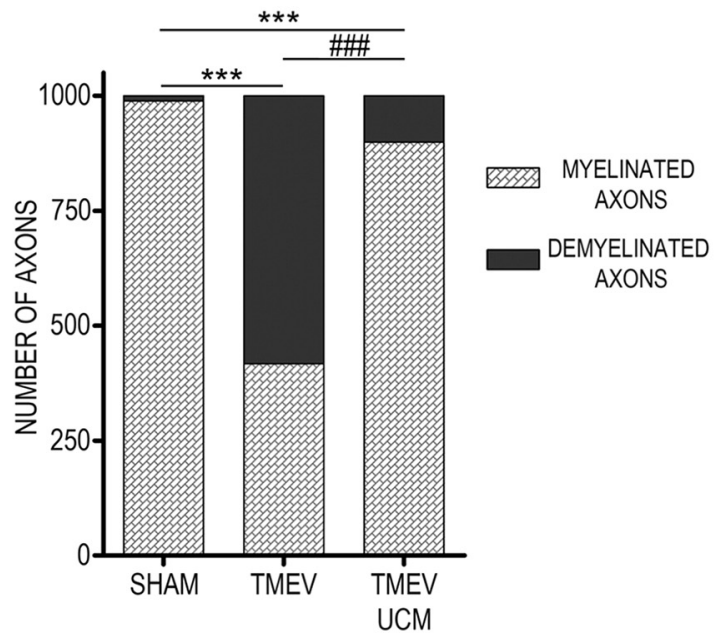

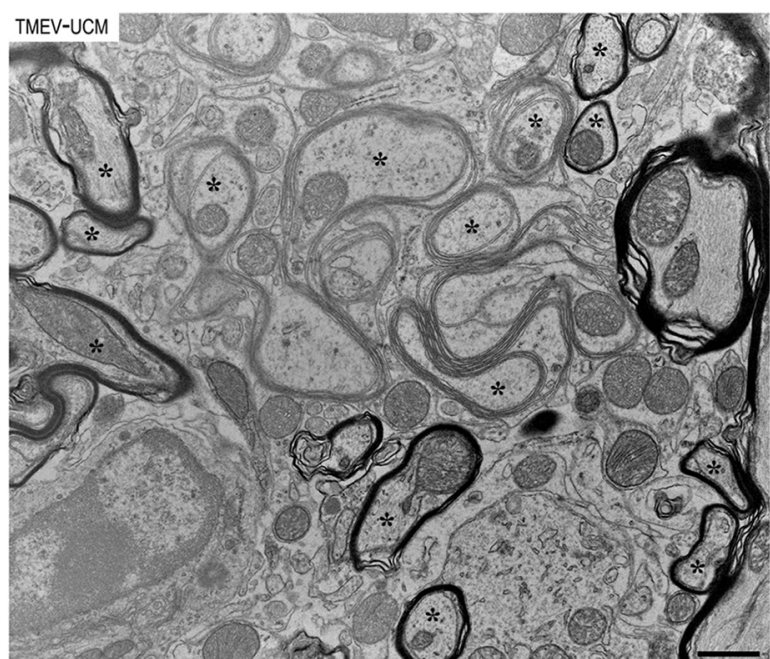

C

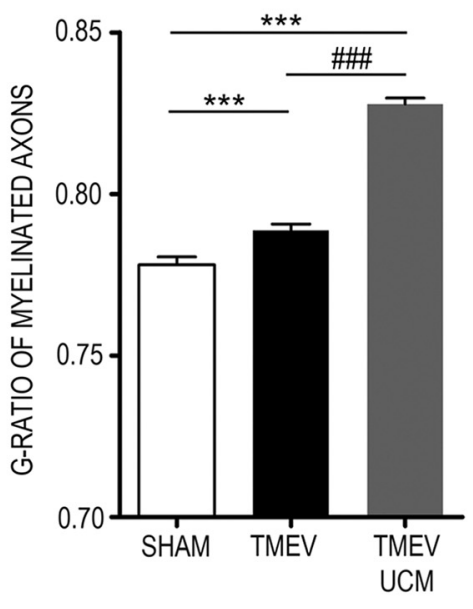

Figure 7. UCM03025 treatment enhances remyelination. Ultrastructural assessment of the myelin and axons by using electron microscopy at 105 dpi $(\boldsymbol{A})$. UCM03025 treatment reduced the number of demyelinated axons in TMEV-infected mice and promoted remyelination (asterisks) in the ventral horn white matter of cervical spinal cords. Scale bars, $1 \mu \mathrm{m}$. Note the loss of myelin and unstructured myelin sheaths in TMEV (417 of 1000 axons) compared with sham and the increase in myelinated axons in UCM03025 (899 of 1000 axons) $(\boldsymbol{B})$. $^{* * *} p<0.001$ ( $\chi^{2}$ test). ${ }^{\# \# \# ~} p<0.001$ ( $\chi^{2}$ test). The $g$-ratios from the axons in UCM03025 were significantly higher than in sham and TMEV (C). Data are the mean \pm SEM. ${ }^{* * *} p<0.001$ (Kruskal-Wallis one-way AN0VA, and pairwise multiple comparisons were done using the Dunn's method). ${ }^{\# \# ~} p<0.001$ (Kruskal-Wallis one-way ANOVA, and pairwise multiple comparisons were done using the Dunn's method).

versibly, eliciting pharmacological tolerance when administered chronically.

Neurodegeneration associated to axonal loss is the cause of the progressive disability in MS with no effective therapies. The enhanced remyelination in the spinal cord of TMEV mice subjected to the blockade of MAGL is consistent with increased expression of oligodendrocyte precursor markers, increased number of mature $\mathrm{CC}^{+}$oligodendrocytes, and increased expression of MBP. These above changes might be able to initiate remyelination in the absence of CSPGs and, thus, contribute to preserve axonal integrity and neuronal function as reflected the recovery of motor function in TMEV mice. In demyelinating pathologies, most remyelinating oligodendrocytes are derived from the distant parenchyma (Polito and Reynolds, 2005), although neurogenic niches may also contribute to remyelination (Nait-Oumesmar et al., 1999; PicardRiera et al., 2002; Menn et al., 2006; Mecha et al., 2013). In general, a lack of remyelination has been attributed to insufficient OPC proliferation and differentiation, whereas in TMEV-IDD a dysregulation of OPC maturation has been proposed as the main cause for the limited remyelination (Ulrich et al., 2008).

To clarify whether the increment in OPC markers, mature oligodendrocytes, and MBP expression in the spinal cord of
TMEV mice could elicit functional remyelination, we analyzed these mice at $105 \mathrm{dpi}$ (20 d after withdrawing UCM03025), a stage that is considered optimal to evaluate remyelination induced by any event (Warrington et al., 2000). UCM03025 did appear to have long-term effects on motor behavior and on CSPGs downregulation, likely by enhancing endogenous repair mechanisms as a significant remyelination reflected by g-ratios measurement of myelinated axons in sham, TMEV, and UCM03025 TMEV-treated mice. Elevated 2-AG tone induced a higher percentage of remyelinated axons; and despite the thin myelin as demonstrate the higher g-ratio in UCM03025 TMEV-treated mice, this process appears to be enough to preserve axonal integrity. Neurofilament-H and BDA tracer results showed the existence of a better functional transport in spinal cord axons. Hence, at least partial axonal preservation does appear to occur, and the axons present are also functionally competent as motor recovery was observed in UCM03025-treated TMEV mice.

In light of the relevance of CSPGs accumulation to impaired remyelination in MS (Siebert and Osterhout, 2011; Lau et al., 2012), it is greatly positive to have a therapy that can promote the proliferation and maturation of oligodendrocytes, as well as to 
overcome the CSPGs barrier. Our findings support the hypothesis that $\mathrm{CB} 1$ and $\mathrm{CB} 2$ receptor-mediated attenuation of TMEVIDD by MAGL inhibition could be due to limited CSPGs production by astrocytes, neutralizing the inhibitory environment in demyelinated areas. This effect appears to be coupled to increased OPC differentiation, which in turn might contribute to remyelination and axonal protection. Additionally, we hypothesize that motor improvement of TMEV mice treated with UCM03025 could also be due to the immunomodulatory properties of 2-AG as attenuated neuroinflammation occurs in TMEV mice as it has been also reported in the experimental model of EAE (Hernández-Torres et al., 2014). Alternatively, antiexcitotoxic, neuroprotective, and glioprotective effects derived from the activation of CB1 and CB2 receptors in neurons, glial cells, and immune infiltrates may be contributing to the benefits of UCM03025 (Arévalo-Martín et al., 2003; Croxford and Miller, 2003; Pryce et al., 2003; Fernández-Ruiz et al., 2010; Loría et al., 2010).

It should be noted that there are still many unsolved questions about the relationship between CSPGs and oligodendroglial cells, as well as the contribution of other lesion's associated factors that inhibit remyelination, such as Notch, Wnt, Lingo-1, and semaphorins (Huang et al., 2011). The protective effect of UCM03025 against chronic myelin loss and its capability to enhance remyelination in a progressive model of MS open new strategies targeting MAGL for the treatment of progressive phases of chronic demyelinating diseases and of other pathologies involving white matter injury.

\section{References}

Arévalo-Martín A, Vela JM, Molina-Holgado E, Borrell J, Guaza C (2003) Therapeutic action of cannabinoids in a murine model of multiple sclerosis. J Neurosci 23:2511-2516. Medline

Arévalo-Martin A, Garcia-Ovejero D, Molina-Holgado E (2010) The endocannabinoid 2-arachidonoylglycerol reduces lesion expansion and white matter damage after spinal cord injury. Neurobiol Dis 38:304-312. CrossRef Medline

Avnur Z, Geiger B (1984) Immunocytochemical localization of native chondroitin-sulfate in tissues and cultured cells using specific monoclonal antibody. Cell 38:811-822. CrossRef Medline

Back SA, Tuohy TM, Chen H, Wallingford N, Craig A, Struve J, Luo NL, Banine F, Liu Y, Chang A, Trapp BD, Bebo BF Jr, Rao MS, Sherman LS (2005) Hyaluronan accumulates in demyelinated lesions and inhibits oligodendrocyte progenitor maturation. Nat Med 11:966-972. CrossRef Medline

Bartus K, James ND, Didangelos A, Bosch KD, Verhaagen J, Yáñez-Muñoz RJ, Rogers JH, Schneider BL, Muir EM, Bradbury EJ (2014) Large-scale chondroitin sulfate proteoglycan digestion with chondroitinase gene therapy leads to reduced pathology and modulates macrophage phenotype following spinal cord contusion injury. J Neurosci 34:4822-4836. CrossRef Medline

Bernal-Chico A, Canedo M, Manterola A, Victoria Sánchez-Gómez M, PérezSamartín A, Rodríguez-Puertas R, Matute C, Mato S (2015) Blockade of monoacylglycerol lipase inhibits oligodendrocyte excitotoxicity and prevents demyelination in vivo. Glia 63:163-176. CrossRef Medline

Carulli D, Rhodes KE, Brown DJ, Bonnert TP, Pollack SJ, Oliver K, Strata P, Fawcett JW (2006) Composition of perineuronal nets in the adult rat cerebellum and the cellular origin of their components. J Comp Neurol 494:559-577. CrossRef Medline

Chang A, Tourtellotte WW, Rudick R, Trapp BD (2002) Premyelinating oligodendrocytes in chronic lesions of multiple sclerosis. N Engl J Med 346:165-173. CrossRef Medline

Chang A, Staugaitis SM, Dutta R, Batt CE, Easley KE, Chomyk AM, Yong VW, Fox RJ, Kidd GJ, Trapp BD (2012) Cortical remyelination: a new target for repair therapies in multiple sclerosis. Ann Neurol 72:918-926. CrossRef Medline

Compston A, Coles A (2008) Multiple sclerosis. Lancet 372:1502-1517. CrossRef Medline

Croxford JL, Miller SD (2003) Immunoregulation of a viral model of mul- tiple sclerosis using the synthetic cannabinoid R+WIN55,212. J Clin Invest 111:1231-1240. CrossRef Medline

Denic A, Wootla B, Zoecklein L, Rodriguez M (2014) Deletion of virusspecific T-cells enhances remyelination in a model of multiple sclerosis. J Neurol Transl Neurosci 2:1032. Medline

Docagne F, Muñetón V, Clemente D, Ali C, Loría F, Correa F, Hernangómez M, Mestre L, Vivien D, Guaza C (2007) Excitotoxicity in a chronic model of multiple sclerosis: neuroprotective role of cannabinoids through CB1 and CB2 receptor activation. Mol Cell Neurosci 34:551-561. CrossRef Medline

Dyck SM, Alizadeh A, Santhosh KT, Proulx EH, Wu CL, Karimi-Abdolrezaee S (2015) Chondroitin sulfate proteoglycans negatively modulate spinal cord neural precursor cells by signaling through LAR and RPTP $\sigma$ and modulation of the Rho/ROCK pathway. Stem Cells 33:2550-2563. CrossRef Medline

Feliú A, Moreno-Martet M, Mecha M, Carrillo-Salinas FJ, de Lago E, Fernández-Ruiz J, Guaza C (2015) A Sativex $\left({ }^{\circledR}\right)$-like combination of phytocannabinoids as a disease-modifying therapy in a viral model of multiple sclerosis. Br J Pharmacol 172:3579-3595. CrossRef Medline

Fernández-Ruiz J, García C, Sagredo O, Gómez-Ruiz M, de Lago E (2010) The endocannabinoid system as a target for the treatment of neuronal damage. Expert Opin Ther Targets 14:387-404. CrossRef Medline

Franklin RJ (2002) Why does remyelination fail in multiple sclerosis? Nat Rev Neurosci 3:705-714. CrossRef Medline

Frischer JM, Weigand SD, Guo Y, Kale N, Parisi JE, Pirko I, Mandrekar J, Bramow S, Metz I, Brück W, Lassmann H, Lucchinetti CF (2015) Clinical and pathological insights into the dynamic nature of the white matter multiple sclerosis plaque. Ann Neurol 78:710-721. CrossRef Medline

Galtrey CM, Fawcett JW (2007) The role of chondroitin sulfate proteoglycans in regeneration and plasticity in the central nervous system. Brain Res Rev 54:1-18. CrossRef Medline

Goldschmidt T, Antel J, König FB, Brück W, Kuhlmann T (2009) Remyelination capacity of the MS brain decreases with disease chronicity. Neurology 72:1914-1921. CrossRef Medline

Gómez O, Arévalo-Martin A, Garcia-Ovejero D, Ortega-Gutierrez S, Cisneros JA, Almazan G, Sánchez-Rodriguez MA, Molina-Holgado F, MolinaHolgado E (2010) The constitutive production of 2-arachidonoylglycerol participates in oligodendrocyte differentiation. Glia 58:1913-1927. CrossRef Medline

Gómez O, Sanchez-Rodriguez A, Le M, Sanchez-Caro C, Molina-Holgado F, Molina-Holgado E (2011) Cannabinoid receptor agonists modulate oligodendrocyte differentiation by activating PI3K/Akt and the mammalian target of rapamycin (mTOR) pathways. Br J Pharmacol 163:1520-1532. CrossRef Medline

Gómez O, Sánchez-Rodríguez MA, Ortega-Gutiérrez S, Vazquez-Villa $\mathrm{H}$, Guaza C, Molina-Holgado F, Molina-Holgado E (2015) A basal tone of 2 -arachidonoylglycerol contributes to early oligodendrocyte progenitor proliferation by activating phosphatidylinositol 3-kinase (PI3K)/AKT and the mammalian target of rapamycin (mTOR) pathways. J Neuroimmune Pharmacol 10:309-317. CrossRef Medline

Haist V, Ulrich R, Kalkuhl A, Deschl U, Baumgärtner W (2012) Distinct spatio-temporal extracellular matrix accumulation within demyelinated spinal cord lesions in Theiler's murine encephalomyelitis. Brain Pathol 22:188-204. CrossRef Medline

Hamby ME, Sofroniew MV (2010) Reactive astrocytes as therapeutic targets for CNS disorders. Neurotherapeutics 7:494-506. CrossRef Medline

Hernández-Torres G, Cipriano M, Hedén E, Björklund E, Canales Á, Zian D, Feliú A, Mecha M, Guaza C, Fowler CJ, Ortega-Gutiérrez S, LópezRodríguez ML (2014) A reversible and selective inhibitor of monoacylglycerol lipase ameliorates multiple sclerosis. Angew Chem Int Ed Engl 53:13765-13770. CrossRef Medline

Huang JK, Franklin RJ (2011) Regenerative medicine in multiple sclerosis: identifying pharmacological targets of adult neural stem cell differentiation Neurochem Int 59:329-332. CrossRef Medline

Keough MB, Rogers JA, Zhang P, Jensen SK, Stephenson EL, Chen T, Hurlbert MG, Lau LW, Rawji KS, Plemel JR, Koch M, Ling CC, Yong VW (2016) An inhibitor of chondroitin sulfate proteoglycan synthesis promotes central nervous system remyelination. Nat Commun 7:11312. CrossRef Medline

Lang BT, Cregg JM, DePaul MA, Tran AP, Xu K, Dyck SM, Madalena KM, Brown BP, Weng YL, Li S, Karimi-Abdolrezaee S, Busch SA, Shen Y, Silver 
J (2015) Modulation of the proteoglycan receptor PTP $\sigma$ promotes recovery after spinal cord injury. Nature 518:404-408. CrossRef Medline

Lassmann H, Brück W, Lucchinetti C (2001) Heterogeneity of multiple sclerosis pathogenesis: implications for diagnosis and therapy. Trends Mol Med 7:115-121. CrossRef Medline

Lau LW, Keough MB, Haylock-Jacobs S, Cua R, Döring A, Sloka S, Stirling DP, Rivest S, Yong VW (2012) Chondroitin sulfate proteoglycans in demyelinated lesions impair demyelination. Ann Neurol 72:419-432. CrossRef Medline

Lipton HL, Dal Canto MC (1976) Chronic neurologic disease in Theiler's virus infection of SJL/J mice. J Neurol Sci 30:201-207. CrossRef Medline

Lledó A, Borrell J, Guaza C (1999) Dexamethasone regulation of interleukin-1receptors in the hippocampus of Theiler's virus-infected mice: effects on virus-mediated demyelination. Eur J Pharmacol 372:75-83. CrossRef Medline

Loría F, Petrosino S, Hernangómez M, Mestre L, Spagnolo A, Correa F, Di Marzo V, Docagne F, Guaza C (2010) An endocannabinoid tone limits excitotoxicity in vitro and in a model of multiple sclerosis. Neurobiol Dis 37:166-176. CrossRef Medline

Lourbopoulos A, Grigoriadis N, Lagoudaki R, Touloumi O, Polyzoidou E, Mavromatis I, Tascos N, Breuer A, Ovadia H, Karussis D, Shohami E, Mechoulam R, Simeonidou C (2011) Administration of 2-arachidonoylglycerol ameliorates both acute and chronic experimental autoimmune encephalomyelitis. Brain Res 1390:126-141. CrossRef Medline

Mecha M, Torrao AS, Mestre L, Carrillo-Salinas FJ, Mechoulam R, Guaza C (2012) Cannabidiol protects oligodendrocyte progenitor cells from inflammation-induced apoptosis by attenuating endoplasmic reticulum stress. Cell Death Dis 3:e331. CrossRef Medline

Mecha M, Feliú A, Carrillo-Salinas FJ, Mestre L, Guaza C (2013) Mobilization of progenitors in the subventricular zone to undergo oligodendrogenesis in the Theiler's virus model of multiple sclerosis: implications for remyelination at lesions sites. Exp Neurol 250:348-352. CrossRef Medline

Mei F, Lehmann-Horn K, Shen YA, Rankin KA, Stebbins KJ, Lorrain DS, Pekarek K, A Sagan S, Xiao L, Teuscher C, von Büdingen HC, Wess J, Lawrence JJ, Green AJ, Fancy SP, Zamvil SS, Chan JR (2016) Accelerated remyelination during inflammatory demyelination prevents axonal loss and improves functional recovery. eLife 5:e18246. CrossRef Medline

Menn B, Garcia-Verdugo JM, Yaschine C, Gonzalez-Perez O, Rowitch D, Alvarez-Buylla A (2006) Origin of oligodendrocytes in the subventricular zone of the adult brain. J Neurosci 26:7907-7918. CrossRef Medline

Molina-Holgado E, Vela JM, Arévalo-Martín A, Almazán G, MolinaHolgado F, Borrell J, Guaza C (2002) Cannabinoids promote oligodendrocyte progenitor survival: involvement of cannabinoid receptors and phosphatidylinositol-3 kinase/Akt signaling. J Neurosci 22:9742-9753. Medline

Nait-Oumesmar B, Decker L, Lachapelle F, Avellana-Adalid V, Bachelin C, Baron-Van Evercooren A (1999) Progenitor cells of the adult mouse subventricular zone proliferate, migrate and differentiate into oligodendrocytes after demyelination. Eur J Neurosci 11:4357-4366. CrossRef Medline

Nash B, Ioannidou K, Barnett SC (2011) Astrocyte phenotypes and their relationship to myelination. J Anat 219:44-52. CrossRef Medline
Pendleton JC, Shamblott MJ, Gary DS, Belegu V, Hurtado A, Malone ML, McDonald JW (2013) Chondroitin sulfate proteoglycans inhibit oligodendrocyte myelination through PTP $\sigma$. Exp Neurol 247:113-121. CrossRef Medline

Picard-Riera N, Decker L, Delarasse C, Goude K, Nait-Oumesmar B, Liblau R, Pham-Dinh D, Baron-Van Evercooren A (2002) Experimental autoimmune encephalomyelitis mobilizes neural progenitors from the subventricular zone to undergo oligodendrogenesis in adult mice. Proc Natl Acad Sci U S A 99:13211-13216. CrossRef Medline

Pihlaja R, Takkinen J, Eskola O, Vasara J, López-Picón FR, Haaparanta-Solin M, Rinne JO (2015) Monoacylglycerol lipase inhibitor JZL184 reduces neuroinflammatory response in APdE9 mice and in adult mouse glial cells. J Neuroinflammation 12:81. CrossRef Medline

Polito A, Reynolds R (2005) NG2-expressing cells as oligodendrocyte progenitors in the normal and demyelinated adult central nervous system. J Anat 207:707-716. CrossRef Medline

Pryce G, Ahmed Z, Hankey DJ, Jackson SJ, Croxford JL, Pocock JM, Ledent C, Petzold A, Thompson AJ, Giovannoni G, Cuzner ML, Baker D (2003) Cannabinoids inhibit neurodegeneration in models of multiple sclerosis. Brain 126:2191-2202. CrossRef Medline

Rolls A, Shetchter R, London A, Segev Y, Jacob-Hirsch J, Amariglio N, Rechavi G, Schwartz M (2008) Two faces of chondroitin sulfate proteoglycan in spinal cord repair: a role in microglial/macrophage activation. PLoS Med 5:1262-1276. CrossRef Medline

Siebert JR, Osterhout DJ (2011) The inhibitory effects of chondroitin sulfate proteoglycans on oligodendrocytes. J Neurochem 119:176-188. CrossRef Medline

Siebert JR, Stelzner DJ, Osterhout DJ (2011) Chondroitinase treatment following spinal contusion injury increases migration of oligodendrocyte progenitor cells. Exp Neurol 231:19-29. CrossRef Medline

Silver J, Miller JH (2004) Regeneration beyond the glial scar. Nat Rev Neurosci 5:146-156. CrossRef Medline

Sobel RA, Ahmed AS (2001) White matter extracellular matrix chondroitin sulfate/dermatan sulfate proteoglycans in multiple sclerosis. J Neuropathol Exp Neurol 60:1198-1207. CrossRef Medline

Ulrich R, Seeliger F, Kreutzer M, Germann PG, Baumgärtner W (2008) Limited remyelination in Theiler's murine encephalomyelitis due to insufficient oligodendroglial differentiation of nerve/glial antigen 2 (NG2)positive putative oligodendroglial progenitor cells. Neuropathol Appl Neurobiol 34:603-620. CrossRef Medline

Warrington AE, Asakura K, Bieber AJ, Ciric B, Van Keulen V, Kaveri SV, Kyle RA, Pease LR, Rodríguez M (2000) Human monoclonal antibodies reactive to oligodendrocytes promote remyelination in a model of multiple sclerosis. Proc Natl Acad Sci U S A 97:6820-6825. CrossRef Medline

Zhao RR, Fawcett JW (2013) Combination treatment with chondroitinase ABC in spinal cord injury-breaking the barrier. Neurosci Bull 29:477483. CrossRef Medline

Zhou HX, Li XY, Li FY, Liu C, Liang ZP, Liu S, Zhang B, Wang TY, Chu TC, Lu L, Ning GZ, Kong XH, Feng SQ (2014) Targeting RPTP $\sigma$ with lentiviral shRNA promotes neurites outgrowth of cortical neurons and improves functional recovery in a rat spinal cord contusion model. Brain Res 1586:46-63. CrossRef Medline 